\title{
Catálogo de polen en mieles de Apis mellifera provenientes de zonas cafeteras en la Sierra Nevada de Santa Marta, Magdalena, Colombia
}

Paula María Montoya-Pfeiffer',*, Daniela León-Bonilla ${ }^{1}$, Guiomar Nates-Parra ${ }^{1}$

${ }^{1}$ Laboratorio de Investigaciones en Abejas LABUN, Departamento de Biología, Facultad de Ciencias, Universidad Nacional de Colombia

${ }^{2}$ Laboratorio de Abelhas, Departamento de Ecologia, Instituto de Biociências, Universidade de São Paulo

\begin{abstract}
Resumen
Se presentan las descripciones morfológicas y fotografías de los granos de polen de 122 especies distribuidas en 54 familias, correspondientes a morfotipos encontrados en miel de Apis mellifera producida en la Sierra Nevada de Santa Marta. Se incluye información adicional sobre nombres comunes, presencia de nectarios, rangos de abundancia en la miel y observaciones ecológicas complementarias. Las familas que aportan el mayor número de especies son las siguientes: Asteraceae, Fabaceae, Malvaceae, Euphorbiaceae, Melastomataceae, Myrtaceae, Poaceae y Sapindaceae. Entre las especies nectaríferas predominantes en la miel se encuentran Austroeupatorium inulifolium, Critonia morifolia, Bursera simaruba, Croton hirtus (Croton spp.), Gliricidia sepium, Inga oerstediana, Adenaria floribunda, Heliocarpus americanus, Muntingia calabura, Rubus urticifolius (Rubus spp.), Coffea arabica y Vitis tiliifolia. Entre las especies no productoras de néctar aparecen como predominantes Astronium graveolens, Carludovica palmata, Begonia guaduensis (Begonia spp.), Trema micrantha, Hediosmum racemosum, Doliocarpus dentatus, Mimosa albida, Mimosa pudica, Poulsenia armata (Moraceae spp.), Piper aduncum (Piper spp.) y Cecropia peltata. Este trabajo se realizó con el fin de aportar una herramienta para los trabajos en melisopalinología que se vienen desarrollando en las regiones cafeteras de la Sierra Nevada de Santa Marta y otras zonas de Colombia.

Palabras clave: abejas, apicultura, melisopalinología, néctar, polen
\end{abstract}

Pollen catalog for Apis mellifera honey from coffee regions in the Sierra Nevada de Santa Marta, Magdalena, Colombia

\begin{abstract}
We present pollen grain morphological descriptions and photographies of 122 species distributed in 54 families, corresponding to morfotypes found in Apis mellifera honey produced in the Sierra Nevada de Santa Marta. Additional information about common names, presence of necteries, abundance range and complementary ecological observations is included. The families with the most number of species were Asteraceae, Fabaceae, Malvaceae, Euphorbiaceae, Melastomataceae, Myrtaceae, Poaceae and Sapindaceae. Preponderant nectar species were Austroeupatorium inulifolium, Critonia morifolia, Bursera simaruba, Croton hirtus (Croton spp.), Gliricidia sepium, Inga oerstediana, Adenaria floribunda, Heliocarpus americanus, Muntingia calabura, Rubus urticifolius (Rubus spp.), Coffea arabica and Vitis tiliifolia. Major nectarless species were Astronium graveolens, Carludovica palmata, Begonia guaduensis (Begonia spp.), Trema micrantha, Hediosmum racemosum, Doliocarpus dentatus, Mimosa albida, Mimosa pudica, Poulsenia armata (Moraceae spp.), Piper aduncum (Piper spp.) and Cecropia peltata. This catalog was done with the aim of providing a work tool for melisopalynological analysis undertaken in the Sierra Nevada de Santa Marta and other coffee-growing regions in Colombia.
\end{abstract}

Key words: Beekeeping, bees, melisopalinology, nectar, pollen.

\section{Introducción}

Cuando las abejas van a las flores en busca de alimento, algunos granos de polen quedan adheridos a su cuerpo o permanecen inmersos en el néctar que recogen, de manera que los granos son transportados hasta las colmenas y luego pueden encontrarse en la miel cosechada y comercializada por los apicultores. El estudio de estos granos de polen, o melisopalinología, constituye una herramienta metodológica fundamental para reconocer el origen botánico de la miel y diferenciarla según las características físicoquímicas,

\footnotetext{
*Correspondencia:

Paula María Montoya Pfeiffer, pmmontoyap@unal.edu.co

Recibido: 25 de junio de 2014

Aceptado: 16 de octubre de 2014
} 
microbiológicas y sensoriales que obedecen a dicho origen (Crane, 1985). Además, en la miel se encuentran granos de polen que sirven a las abejas como fuente de proteína y que, aunque no proveen información sobre el origen botánico, sirven de indicadores del origen geográfico, el cual también representa un parámetro de diferenciación de la miel (Von der Ohe, et al., 2004).

En este sentido, los catálogos polínicos facilitan en gran medida el proceso de identificación de las especies vegetales que dan origen a la miel. Si bien ya existen varios catálogos para las especies colombianas (por ejemplo los elaborados por Hooghiemstra, 1984, Jiménez \& Rangel, 1997, Velásquez, 1999, Rangel \& Bogotá, 2001), todavía no se ha realizado un trabajo completo enfocado en plantas melíferas que incluya tanto fotografias como descripciones morfológicas (Girón-Vanderhuck, 1995 y Giraldo, et al., 2011, presentan únicamente fotografías). Con este trabajo se buscó aportar un documento de referencia para los análisis melisopalinológicos que se vienen desarrollando en las zonas cafeteras de la Sierra Nevada de Santa Marta (León-Bonilla, en preparación), además de complementar los trabajos realizados por Nates-Parra, et al., (2013) y Giraldo, et al., (2011). Se presenta, igualmente, información complementaria sobre nombres comunes, rangos de abundancia en la miel, presencia de nectarios y otras observaciones ecológicas que servirán para facilitar la determinación del origen botánico y geográfico de la miel de estas regiones.

\section{Metodología}

El area de estudio comprende la vertiente occidental de la Sierra Nevada de Santa Marta (SNSM), entre los 500 y los $2.000 \mathrm{msnm}$, aproximadamente; la temperatura fluctúa entre 12 y $24{ }^{\circ} \mathrm{C}$ y la precipitación es de 500 a $7.000 \mathrm{~mm}^{3}$. La vegetación natural se clasifica en siete zonas de vida según Holdridge: bosque muy seco tropical (bms-T), bosque seco tropical (bs-T), bosque húmedo tropical (bh-T), bosque húmedo subtropical (bh-ST), bosque húmedo montano bajo (bh-MB), bosque muy húmedo montano bajo (bmhMB) y bosque muy húmedo montano (bmh-M) (Espinal \& Montenegro, 1963). Se estima que la cobertura vegetal original se ha reducido en un 70 a $80 \%$ como resultado del desarrollo de cultivos de café principalmente, así como de la ganadería y otros cultivos menores como la caña de azúcar, el cacao y el plátano, entre otros (Anónimo, 2003).

Para realizar este catálogo se seleccionaron 122 especies que fueron identificadas a partir de los análisis melisopalinológicos llevados a cabo por Nates-Parra, et al., (2013) y León-Bonilla (en preparación). Para el caso de los morfotipos identificados únicamente a nivel de familia o género, se escogió una especie que estuviera bien representada en la región con base en listados de plantas comunes de la SNSM (Anónimo, 2013) y ejemplares depositados en el Herbario Nacional Colombiano.
Se describieron los granos de polen a partir de ejemplares de referencia acetolizados (Erdtman, 1943) y depositados en las colecciones palinológicas del Laboratorio de Investigaciones en Abejas del Departamento de Biología de la Facultad de Ciencias de la Universodad Nacional (LABUN) y del Instituto de Ciencias Naturales (ICN), utilizando un microscopio óptico Leica DM500 con 1.000 aumentos, contraste de fases y reglilla micrométrica ocular. Se hicieron mediciones en diez granos de cada especie seleccionados aleatoriamente para calcular los rangos de diámetro polar (DP) y diámetro ecuatorial (DE), el grosor de exina, las dimensiones de colpos, poros, ornamentos de la exina y apocolpio. Se empleó la terminología del glosario elaborado por Punt, et al., (2007), con las traducciones al español propuestas por Velásquez (1999) y las categorías de forma (basadas en la proporción DP/DE) y ámbito definidas por Erdtman (1943). Las fotografías se tomaron a 100x con una cámara Leica ICC50 HD y el programa Leica Application Suite LAS EZ versión 2.1.0.

Se recopiló información adicional de las especies relativa a los nombres comunes (Bernal, et al., 2013; Anónimo, 2013), las observaciones ecológicas (tomadas de ejemplares depositados en el Herbario Nacional Colombiano), la presencia o ausencia de nectarios (revisados en su mayoría por Nicolson, et al., 2007) y los rangos de abundancia en las muestras de miel: dominante (D) $>45 \%$, secundario (S) 15 a $45 \%$, importante aislado (IA) $3-<15 \%$, aislado (A) $<3 \%$ (Louveaux, et al., 1970, Nates-Parra, et al., 2013, LeónBonilla, en preparación).

\section{Resultados}

A continuación se presentan las descripciones de 122 especies agrupadas en 54 familias, entre las cuales 12 (4 familias) son de la clase Liliopsida y 110 (50 familias) son de la Magnoliopsida. Las abreviaturas utilizadas en las descripciones son las siguientes: $\mathrm{DE}=$ distancia ecuatorial, $\mathrm{DP}=$ distancia polar y M.E.= muestra estudiada. Las especies que aparecen como polen dominante y secundario en la miel de la Sierra Nevada de Santa Marta (véase tabla 1) se presentan en las figuras 1 a 5, y las especies aisladas e importantesaisladas aparecen como material suplementario en las figuras $1 \mathrm{~S}$ a $16 \mathrm{~S}$.

\section{CLASE LILIOPSIDA O MONOCOTILEDONEAS}

\section{ARECACEAE}

Bactris gasipaes var. chichagui (H.Karst.) A.J.Hend. (Figura 1S, https://www.raccefyn.co/index.php/raccefyn/ article/view/61/668; No. 1)

Granos dimórficos con simetría radial o bilateral, heteropolares, monocolpados o tricotomocolpados, oblados a esferoidales, ámbito elíptico o triangular convexo; DE: 40-47, DP: 26-45 $\mu \mathrm{m}$. Exina: 1,5-2 $\mu \mathrm{m}$ de grosor, columelada y fosulada. M.E.: ICN 3135. 
Tabla 1. Listado de las especies descritas con información sobre nombres comunes, rango de abundancia relativa (AR) en la muestras de miel y observaciones ecológicas

\begin{tabular}{|c|c|c|c|c|}
\hline Familia & Nombre científico & Nombres comunes & $\mathbf{A R}$ & Observaciones ecológicas \\
\hline \multirow{4}{*}{ Arecaceae } & Bactris gasipaes var. chichagu* & Macana & A-IA ${ }^{1}$ & Palma de bosques húmedos, entre 250 y $1.500 \mathrm{~m}$ \\
\hline & Dictyocaryum lamarckianum? & Tagua, mapora & A-D & Palma de bosques húmedos, entre 800 y $1.000 \mathrm{~m}$ \\
\hline & Euterpe precatoria & Maquenque & A & Palma de bosques húmedos, entre 5 y $2.000 \mathrm{~m}$ \\
\hline & Geonoma interrupta & cortadera, cola de gallo & $\mathrm{A}^{1}$ & Palma de bosques primarios y secundarios y sabanas, entre 0 y $1.800 \mathrm{~m}$ \\
\hline Cyclanthaceae & Carludovica palmata* & Iraca, jiraca & A-D & Arbusto frecuente en bosques húmedos primarios o secundarios, entre 70 y $1.420 \mathrm{~m}$ \\
\hline \multirow{2}{*}{ Cyperaceae } & Rhynchospora barbata* & Pasto estrella & A-IA ${ }^{1}$ & Hierba frecuente en áreas abiertas, entre 80 y $1.000 \mathrm{~m}$ \\
\hline & Scleria mitis* & Cortadera & A-IA ${ }^{1}$ & Hierba frecuente en márgenes de ríos y ciénagas y áreas abiertas, entre 20 y $1.000 \mathrm{~m}$ \\
\hline \multirow{5}{*}{ Poaceae } & Brachiaria brizantha* & Brachiaria & $\mathrm{A}-\mathrm{IA}^{2}$ & Pasto introducido y cultivado entre $0-2.000 \mathrm{~m}$ \\
\hline & Holcus lanatus* & Pasto poa, pasto lanudo & $\mathrm{A}-\mathrm{IA}^{2}$ & Pasto introducido, frecuente entre $0-4.000 \mathrm{~m}$ \\
\hline & Melinis minutiflora* & Pasto gordura, yaraguá & $\mathrm{A}-\mathrm{IA}^{2}$ & Pasto introducido, frecuente entre $0-3.000 \mathrm{~m}$ \\
\hline & Pennisetum purpureum* & Pasto elefante & $\mathrm{A}-\mathrm{IA}^{2}$ & Pasto introducido, común en áreas abiertas entre $0-2.200 \mathrm{~m}$ \\
\hline & Zea mays* & Maíz & $\mathrm{A}-\mathrm{IA}^{2}$ & Planta cultivada en todas las regiones entre $200-2.600 \mathrm{~m}$ \\
\hline Actinidaceae & Saurauia yasicae* & & A-IA ${ }^{1}$ & $\begin{array}{l}\text { Árbol de bosques primarios, secundarios o de galería, común en el borde de caminos } \\
\text { y cultivos de café, entre } 300-1.300 \mathrm{~m}\end{array}$ \\
\hline Amaranthaceae & Iresine diffusa* & Patepava & A & Hierba frecuente en bosques, matorrales y áreas disturbadas, entre $0-3.500 \mathrm{~m}$ \\
\hline \multirow{3}{*}{ Anacardiaceae } & Anacardium excelsum & Caracolí, mitabi & A-S & Árbol de bosques secos y húmedos tropicales, entre $0-1.400 \mathrm{~m}$ \\
\hline & Astronium graveolens* & Gusanero, quebracho & A-D & Árbol de bosques secos y áreas intervenidas, entre 10-700 m \\
\hline & Mangifera indica & Mango & A & Árbol introducido y cultivado entre $0-1.800 \mathrm{~m}$ \\
\hline Aquifoliaceae & Ilex kunthiana & Palo mulato & A-IA ${ }^{1}$ & Árbol de ecosistemas de alta montaña, entre $2.500-3.950 \mathrm{~m}$ \\
\hline Araliaceae & Oreopanax capitatus & Mano de oso, tinajero & $\mathrm{A}-\mathrm{IA}^{2}$ & $\begin{array}{l}\text { Árbol común en bordes de bosque, remanentes de vegetación y bordes de camino, } \\
\text { entre } 600-2.780 \mathrm{~m}\end{array}$ \\
\hline \multirow{14}{*}{ Asteraceae } & Acmella ciliata & Botoncillo, yuyo, guaca & $\mathrm{A}-\mathrm{IA}^{2}$ & Hierba frecuente en cultivos y bordes de caminos, entre $0-2.600 \mathrm{~m}$ \\
\hline & Austroeupatorium inulifolium & Salvia & A-D & Arbusto común en zonas perturbadas o en recuperación, entre $1.200-2.200 \mathrm{~m}$ \\
\hline & Baccharis trinervis & Chilco, marucha & A-IA ${ }^{1}$ & Arbusto frecuente en áreas abiertas, entre 0-3.000 m \\
\hline & Bidens pilosa & Pacunga & $\mathrm{A}-\mathrm{IA}^{2}$ & Hierba común en áreas intervenidas, cultivos y bordes de caminos, entre 0-3.100 m \\
\hline & Clibadium surinamense & Salvia amarga & $\mathrm{A}^{2}$ & Arbusto común en áreas perturbadas, entre 0-2.800 m \\
\hline & Critonia morifolia & & A-D & Arbusto de bosques húmedos y secos, entre $0-2.200 \mathrm{~m}$ \\
\hline & Eirmocephala brachiata & Tabaquillo, mano de tigre & A-S & Arbusto común cerca de cursos de agua, entre 100-2.200 m \\
\hline & Emilia sonchifolia & Borlita, clavelito & A-IA & Hierba introducida, común en bordes de camino y cultivos, entre $0-2.000 \mathrm{~m}$ \\
\hline & Hypochaeris radicata & Chicoria, diente de león & A-IA & $\begin{array}{l}\text { Hierba introducida común en pastizales, cultivos y bordes de camino, entre } 40-4.500 \\
\mathrm{~m}\end{array}$ \\
\hline & Lepidaploa canescens & Aliso, varejón & $\mathrm{A}-\mathrm{IA}^{2}$ & Arbusto común en zonas perturbadas, entre $400-1.700 \mathrm{~m}$ \\
\hline & Mikania micrantha & Guaco blanco & $\mathrm{A}-\mathrm{IA}^{2}$ & Bejuco común en áreas abiertas y bordes de bosques intervenidos, entre 0-2.900 m \\
\hline & Neurolaena lobata & Contra gavilana & $\mathrm{A}-\mathrm{IA}^{2}$ & Arbusto común en áreas abiertas de zonas cálidas y húmedas, entre $0-2.000 \mathrm{~m}$ \\
\hline & Tithonia diversifolia & Botón de oro & $\mathrm{A}-\mathrm{IA}^{2}$ & Arbusto común en áreas intervenidas, entre 40-2.000 m \\
\hline & Vernonanthura patens & Indioviejo, balsilla & $A-S^{1}$ & $\begin{array}{l}\text { Arbusto común en zonas intervenidas, matorrales y bordes de camino, entre } 0-2.100 \\
\mathrm{~m}\end{array}$ \\
\hline Balsaminaceae & Impatiens walleriana & Besitos & A-IA & $\begin{array}{l}\text { Hierba introducida común en áreas intervenidas, cultivos, jardines y bordes de } \\
\text { caminos, entre 0-2.500 msnm }\end{array}$ \\
\hline Begoniaceae & Begonia guaduensis* & Novio de monte & $A-D^{1}$ & Hierba de bosque húmedo premontano, entre $70-3.000 \mathrm{~m}$ \\
\hline
\end{tabular}




\begin{tabular}{|c|c|c|c|c|}
\hline Bignoniaceae & Tabebuia rosea & Roble & A-IA ${ }^{2}$ & Árbol de bosques y áreas perturbadas, entre $0-2.000 \mathrm{~m}$ \\
\hline \multirow{3}{*}{ Boraginaceae } & Cordia alba & Uvito & A-IA & Árbol de zonas secas, entre $0-1.200 \mathrm{~m}$ \\
\hline & Cordia alliodora & Nogal & A-IA & Árbol de bosques húmedos y zonas cafeteras, entre $0-2.700 \mathrm{~m}$ \\
\hline & Cordia spinescens & Verdenegro & A & Arbusto común en bordes de bosque y caminos, entre $0-2.700 \mathrm{~m}$ \\
\hline Burseraceae & Bursera simaruba & Indiodesnudo, almácigo & A-D & Árbol de bosques secos o áreas húmedas con microclimas secos, entre $0-1.000 \mathrm{~m}$ \\
\hline \multirow{2}{*}{ Cannabaceae } & Celtis iguanaea* & Tala trepador & $\mathrm{A}^{2}$ & Árbol de bosque seco, entre $0-1.100 \mathrm{~m}$ \\
\hline & Trema micrantha* & Majagüito & A-D & Árbol de bosques y áreas perturbadas, entre $0-2.500 \mathrm{~m}$ \\
\hline Chloranthaceae & Hedyosmum racemosum* & Chiflichifli, granizo & A-D & Árbol de interior y bordes de bosques, entre $250-2.900 \mathrm{~m}$ \\
\hline Chrysobalanaceae & Chrysobalanus icaco & Icaco & A-IA ${ }^{2}$ & Arbusto común en litorales y bordes de bosque, entre $0-550 \mathrm{~m}$ \\
\hline Clusiaceae & Clusia multiflora? & Chagualo, caucho, gaque & $\mathrm{A}^{1}$ & $\begin{array}{l}\text { Árbol de bosques andinos, páramos y áreas abiertas con alta humedad, entre } \\
10-3.400 \mathrm{~m}\end{array}$ \\
\hline \multirow{2}{*}{ Convolvulaceae } & Ipomoea batatas & Batata & $\mathrm{A}^{1}$ & Planta trepadora común en áreas disturbadas, entre $0-4.500 \mathrm{~m}$ \\
\hline & Merremia umbellata & Batatillo & A & Planta trepadora común en rastrojos y cultivos, entre $0-2.000 \mathrm{~m}$ \\
\hline Cunoniaceae & Weinmannia pinnata & Encenillo, kokuisha (kogi) & $\mathrm{A}-\mathrm{S}^{1}$ & Arbusto o árbol de bosque húmedo, entre 1.500-3.900 m \\
\hline \multirow{2}{*}{ Dilleniaceae } & Davilla kunthii* & $\begin{array}{l}\text { Bejuco tomé, bejuco } \\
\text { Quemador, }\end{array}$ & A-S & Bejuco de bosque húmedo, entre 0-1.700 m \\
\hline & Doliocarpus dentatus* & bejuco tomé & A-D & Arbusto de bosque húmedo, entre $10-2.000 \mathrm{~m}$ \\
\hline Elaeocarpaceae & Sloanea multiflora & Achiotillo & A-IA ${ }^{1}$ & Árbol de bosques secos y de galería \\
\hline Erythroxylaceae & Erythroxylum novogranatense & Coca & A & Arbusto cultivado en zonas secas y húmedas, entre $150-2.000 \mathrm{~m}$ \\
\hline Escalloniaceae & Escallonia pendula & Tíbar, mangle, loqueto & A-IA ${ }^{1}$ & Árbol encontrado entre $1.100-3.000 \mathrm{~m}$ \\
\hline \multirow{6}{*}{ Euphorbiaceae } & Acalypha macrostachya* & Zanquemula & A-IA & $\begin{array}{l}\text { Árbol común en bordes de bosque, áreas degradadas, matorrales y potreros, entre } \\
\text { 10-2.000 m }\end{array}$ \\
\hline & Alchornea latifolia* & Mazamorro & $\mathrm{A}-\mathrm{IA}^{1}$ & Arbol de bosque húmedo, entre $100-5.000 \mathrm{~m}$ \\
\hline & Croton hirtus & Drago, guacamayo & $A-D^{1}$ & Hierba común en potreros y zonas abiertas, entre $0-1.300 \mathrm{~m}$ \\
\hline & Euphorbia hirta & Lechecillo & A & Hierba común en bordes de camino y zonas disturbadas, entre $0-1.600 \mathrm{~m}$ \\
\hline & Ricinus communis & $\begin{array}{l}\text { Higuerilla, Higuereta, } \\
\text { ricino }\end{array}$ & A-IA & Arbusto introducido, frecuente en zonas disturbadas, entre $20-2.750 \mathrm{~m}$ \\
\hline & Sapium glandulosum & Caucho & A-IA ${ }^{1}$ & Árbol de bosque secundario, entre $0-2.600 \mathrm{~m}$ \\
\hline \multirow{5}{*}{$\begin{array}{l}\text { Fabaceae } \\
\text { (Faboidae) }\end{array}$} & Aeschynomene americana & Dormidera, pegapega & A-IA & Hierba común en áreas ruderales e intervenidas, entre $0-1.900 \mathrm{~m}$ \\
\hline & Erythrina rubrinervia & Chocho & $\mathrm{A}^{1}$ & Árbol que habita al interior de bosques, entre $100-2.700 \mathrm{~m}$ \\
\hline & Gliricidia sepium & Matarratón & A-D & Árbol ampliamente utilizado para cercas vivas, entre $0-2.000 \mathrm{~m}$ \\
\hline & Platymiscium pinnatum & Guayacán trébol & A-S & Árbol de bosques húmedos y semideciduos, entre $0-1.500 \mathrm{~m}$ \\
\hline & Trifolium repens & Carretón, trébol blanco & A & Hierba introducida común en pastizales y áreas intervenidas, entre $1.100-2.300 \mathrm{~m}$ \\
\hline \multirow{4}{*}{$\begin{array}{l}\text { Fabaceae } \\
\text { (Mimosoidae) }\end{array}$} & Inga oerstediana & Guamo & A-D & Árbol común en bosques intervenidos y cafetales, entre $100-2.300 \mathrm{~m}$ \\
\hline & Mimosa albida* & Zarza & A-D & Hierba común en bordes de camino y zonas disturbadas, entre $750-2.600 \mathrm{~m}$ \\
\hline & Mimosa pigra* & Zarza de matorral & A-IA & Hierba o arbusto común en zonas abiertas, entre $0-1.400 \mathrm{~m}$ \\
\hline & Mimosa pudica* & Dormidera & A-D & Hierba común en zonas perturbadas, entre $0-1.800 \mathrm{~m}$ \\
\hline Hypericaceae & Vismia baccifera & Papamo, carate, caratillo & A & Árbol común en potreros, rastrojos altos y remanentes de bosque, entre $800-2.800 \mathrm{~m}$ \\
\hline Icacinaceae & Calatola costaricensis? & Gallinazo & A & Árbol de bosque húmedo, entre 100-2.440 m \\
\hline \multirow{2}{*}{ Lamiaceae } & Hyptis mutabilis & Mastranto & $\mathrm{A}^{2}$ & Arbusto común en zonas alteradas y bordes de camino, entre $100-2.700 \mathrm{~m}$ \\
\hline & Salvia occidentalis & Cansaperro & $\mathrm{A}^{2}$ & Hierba encontrada entre $0-1.300 \mathrm{~m}$ \\
\hline Lauraceae & Persea americana & Aguacate & $\mathrm{A}^{2}$ & Árbol cultivado entre $0-2.000 \mathrm{~m}$ \\
\hline Lythraceae & Adenaria floribunda & Chaparro & A & Árbol de bosques húmedos y muy húmedos, entre $1.000-2.000 \mathrm{~m}$ \\
\hline Malpighiaceae & Stigmaphyllon columbicum* & & $\mathrm{A}^{2}$ & Bejuco encontrado en matorrales y vegetación riparia, entre $60-1.700 \mathrm{~m}$ \\
\hline \multirow{3}{*}{$\begin{array}{l}\text { Malvaceae } \\
\text { (Bombacoidae) }\end{array}$} & Ceiba pentandra & Ceiba, bongo & A & Árbol encontrado en bosques húmedos y de galería, entre $50-220 \mathrm{~m}$ \\
\hline & Ochroma pyramidale & Balso & A & $\begin{array}{l}\text { Árbol de zonas cálidas, húmedas y secas, cerca de cuerpos de agua, zonas abiertas y } \\
\text { cultivos, entre } 0-1.800 \mathrm{~m}\end{array}$ \\
\hline & Pseudobombax septenatum & Majagua, ceibo barrigón & A-IA & Árbol de bosques húmedos, secos, costeros o dunas arenosas, entre $0-1.600 \mathrm{~m}$ \\
\hline $\begin{array}{l}\text { Malvaceae } \\
\text { (Byttnerioidae) }\end{array}$ & Melochia parvifolia & Escoba blanca & A & Arbusto común en áreas perturbadas, pastizales y cultivos, entre $0-1.100 \mathrm{~m}$ \\
\hline
\end{tabular}




\begin{tabular}{|c|c|c|c|c|}
\hline \multirow{2}{*}{$\begin{array}{l}\text { Malvaceae } \\
\text { (Grewioidae) }\end{array}$} & Corchorus orinocensis & Escobilla negra, & A & Arbusto común en áreas perturbadas, entre $0-1.400 \mathrm{~m}$ \\
\hline & Heliocarpus americanus & Balsillo & A-D & Árbol común en áreas perturbadas, entre $0-2.600 \mathrm{~m}$ \\
\hline \multirow{2}{*}{$\begin{array}{l}\text { Malvaceae } \\
\text { (Malvoidae) }\end{array}$} & Abutilon x hybridum & Abutilón & A & Arbusto introducido, usado como planta ornamental en jardines, entre $0-3.000 \mathrm{~m}$ \\
\hline & Sida acuta & Escobo, escoba babosa & $\mathrm{A}^{1}$ & Hierba común en áreas perturbadas, entre $0-1.800 \mathrm{~m}$ \\
\hline \multirow{5}{*}{ Melastomataceae } & Conostegia icosandra* & & $\mathrm{A}-\mathrm{IA}^{2}$ & Árbol de bosque ripario, entre $140-1.450 \mathrm{~m}$ \\
\hline & Miconia dodecandra* & Tuno, cuatrofilos & $\mathrm{A}-\mathrm{IA}^{2}$ & Árbol común en bosques secundarios, rastrojos y áreas intervenidas, entre $50-2.100 \mathrm{~m}$ \\
\hline & Miconia minutiflora & Tuno, nigüito & A-IA ${ }^{1}$ & Arbusto de bosque denso, siempreverde, tropical submontano, entre $0-2.400 \mathrm{~m}$ \\
\hline & Miconia serrulata* & Tuno, mortiño & $\mathrm{A}-\mathrm{IA}^{1}$ & Árbol de bosque húmedo y de galería, entre 120-1.800 m \\
\hline & Tibouchina longifolia & Lengua de buey, chiquilla & $\mathrm{A}-\mathrm{IA}^{2}$ & Hierba de bosques húmedos, secos o de galería, entre $0-3.000 \mathrm{~m}$ \\
\hline \multirow{3}{*}{ Moraceae } & Poulsenia armata* & Cucuá & A-D & Árbol que habita al interior de bosques húmedos, entre $0-2.300 \mathrm{~m}$ \\
\hline & Pseudolmedia laevigata* & Lechechiva, guayabo & $\mathrm{A}-\mathrm{IA}^{2}$ & Árbol que habita al interior de bosques húmedos, entre $0-1.000 \mathrm{~m}$ \\
\hline & Trophis racemosa* & Guáimaro & $\mathrm{A}-\mathrm{IA}^{2}$ & Árbol de bosques húmedos y secos, entre $0-1.000 \mathrm{~m}$ \\
\hline Muntingiaceae & Muntingia calabura & Chitató & A-D & Árbol común en áreas perturbadas, entre $0-1.500 \mathrm{~m}$ \\
\hline \multirow{5}{*}{ Myrtaceae } & Calycolpus moritzianus & Arrayán guayabo & $\mathrm{A}-\mathrm{IA}^{2}$ & Árbol común en bordes de caminos y bosques, entre $700-3.500 \mathrm{~m}$ \\
\hline & Eucalyptus globulus & Eucalipto & A-IA & $\begin{array}{l}\text { Árbol introducido, cultivado en orillas de caminos y terrenos alterados, entre } \\
0-3.500 \mathrm{~m}\end{array}$ \\
\hline & Myrcia splendens & Arrayán sururo & $\mathrm{A}-\mathrm{IA}^{2}$ & Árbol de bosques húmedos secundarios, entre $200-2.800 \mathrm{~m}$ \\
\hline & Psidium guajava & Guayaba & A-IA & $\begin{array}{l}\text { Árbol cultivado y común en orillas de caminos, terrenos alterados y bosques secos, } \\
\text { entre } 0-2.350 \mathrm{~m}\end{array}$ \\
\hline & Syzygium jambos & Pomarroso & A-IA & Árbol introducido y cultivado en áreas húmedas entre 0-2.500 m \\
\hline Oleaceae & Fraxinus chinensis* & Urapán & A-S & Árbol introducido y cultivado en áreas rurales entre 1.500-2.900 m \\
\hline Phyllanthaceae & Hieronyma fendleri? & Motilón, candelo & $\mathrm{A}-\mathrm{S}^{1}$ & Árbol de bosques húmedos, entre $150-1.850 \mathrm{~m}$ \\
\hline Phytolaccaceae & Phytolacca rivinioides & Guaba & A & Hierba o arbusto común en vegetación riparia y rastrojos, entre $100-2.900 \mathrm{~m}$ \\
\hline Piperaceae & Piper aduncum* & Cordoncillo & $A-D^{1}$ & Árbol común en bosques húmedos y secos y áreas perturbadas, entre $0-3.200 \mathrm{~m}$ \\
\hline Polygonaceae & Triplaris americana & Varasanta, palosanto & A & Árbol de bosques secos y húmedos tropicales, entre $0-1.500 \mathrm{~m}$ \\
\hline \multirow{2}{*}{ Primulaceae } & Ardisia guianensis & Cadillo & $\mathrm{A}-\mathrm{S}^{1}$ & Arbusto de bosques húmedos, entre $20-2.400 \mathrm{~m}$ \\
\hline & Cybianthus nevadensis & Cucharo & $\mathrm{A}-\mathrm{D}^{1}$ & Arbusto de bosques húmedos, entre $1.200-3.725 \mathrm{~m}$ \\
\hline Proteaceae & Roupala montana & Mapurito & A-IA ${ }^{1}$ & $\begin{array}{l}\text { Arbusto o árbol común en áreas disturbadas, bosques de galería y sabanas, entre } \\
300-2.000 \mathrm{~m}\end{array}$ \\
\hline Rhamnaceae & Gouania polygama & Limpiadientes, mascapalo & A-S & Árbol común en bosques intervenidos, entre $5-1.700 \mathrm{~m}$ \\
\hline Rosaceae & Rubus urticifolius & Mora silvestre & $A-D^{1}$ & Arbusto común en zonas intervenidas, entre $800-2.700 \mathrm{~m}$ \\
\hline \multirow{3}{*}{ Rubiaceae } & Coffea arabica & Café & A-D & Arbusto introducido y ampliamente cultivado entre $700-2.000 \mathrm{~m}$ \\
\hline & Spermacoce verticillata & Estilo & $\mathrm{A}-\mathrm{IA}^{1}$ & Hierba común en bordes de camino y cultivos, entre $350-3.100 \mathrm{~m}$ \\
\hline & Warszewiczia coccinea & Cresta de gallo, guacamayo & A & Árbol o arbusto de tierras planas, húmedas y con semisombra, entre $0-2.100 \mathrm{~m}$ \\
\hline Rutaceae & Citrus aurantium & Naranja & $\mathrm{A}^{1}$ & Árbol introducido y cultivado entre $0-2.800 \mathrm{~m}$ \\
\hline Salicaceae & Casearia corymbosa & Café del diablo, ondequera & $\mathrm{A}^{2}$ & Árbol de vegetación costera, bosque seco y sabanas, entre $0-1.200 \mathrm{~m}$ \\
\hline \multirow{5}{*}{ Sapindaceae } & Cupania americana & Guacharaco, cariseco & A & Árbol de áreas disturbadas, bordes de carretera y caminos, entre $100-2.800 \mathrm{~m}$ \\
\hline & Melicoccus bijugatus & Mamoncillo, mamón & $\mathrm{A}-\mathrm{S}^{1}$ & Árbol de bosques secos, entre $70-1.500 \mathrm{~m}$ \\
\hline & Melicoccus oliviformis & Mamón cotopli & $\mathrm{A}-\mathrm{S}^{1}$ & Árbol de bosques húmedos, entre $20-800 \mathrm{~m}$ \\
\hline & Paullinia macrophylla & Bejuco prieto & A-IA ${ }^{1}$ & Liana común en bordes de carretera y bosques de galería, entre 120-1.250 m \\
\hline & Serjania paniculata & Bejuco de jabón & A-IA ${ }^{1}$ & Liana que habita entre $20-2.100 \mathrm{~m}$ \\
\hline \multirow[b]{2}{*}{ Solanaceae } & Brugmansia pittieri & Borrachero & $\mathrm{A}^{1}$ & Árbol común en zonas húmedas y disturbadas, entre $1.000-3.200 \mathrm{~m}$ \\
\hline & Solanum aturense & Uña de gato, mataperro & A-IA ${ }^{1}$ & $\begin{array}{l}\text { Árbol que habita en bosque de galería, bosques secundarios y áreas perturbadas, entre } \\
0-3,700 \mathrm{~m}\end{array}$ \\
\hline Urticaceae & Cecropia peltata* & Guarumo & A-D & Árbol de bosques primarios y secundarios, entre $0-2.000 \mathrm{~m}$ \\
\hline \multirow{2}{*}{ Vitaceae } & Cissus verticillata & Bejuco de agua & A & Liana que habita en ambientes naturales y alterados, entre $0-2.100 \mathrm{~m}$ \\
\hline & Vitis tiliifolia & Bejuco de agua & A-D & Liana que habita en bosques húmedos, entre $0-2.000 \mathrm{~m}$ \\
\hline
\end{tabular}

* Plantas que no producen néctar. ${ }^{1}$ Abundacias relativas de las especies que fueron identificadas solo a nivel de género en las muestras de miel. ${ }^{2} \mathrm{Abundancias}$ relativas de las especies que fueron identificadas solo a nivel de familia en las muestras de miel. A: aislado, IA: importante aislado, S: secundario, D: dominante 
Dictyocaryum lamarckianum (Mart.) H.Wendl. (Figura 1, No. 1)

Granos con simetría bilateral, heteropolares, monocolpados, oblados a esferoidales, ámbito elíptico; DE: 15-25, DP: 15$20 \mu \mathrm{m}$. Exina: $2 \mu \mathrm{m}$ de grosor, columelada y areolada, columelas apiladas formando grupos a manera de verrugas. M.E.: ICN 6107.

\section{Euterpe precatoria Mart. (Figura 1S, No. 2)}

Granos con simetría bilateral, heteropolares, monocolpados, peroblados a oblados, ámbito elíptico; DE: 27-40, DP: 13$17 \mu \mathrm{m}$. Exina: 1-1,5 $\mu \mathrm{m}$ de grosor, escabrada. M.E.: ICN 6056.

Geonoma interrupta (Ruiz \& Pav.) Mart. (Figura 1S, No. 3)

Granos con simetría bilateral, heteropolares, monocolpados, oblados a suboblados, ámbito elíptico; DE: 22-28, DP: 15-
$20 \mu \mathrm{m}$. Exina: $<1-1 \mu \mathrm{m}$ de grosor, microreticulada. M.E.: ICN 4429.

\section{CYCLANTHACEAE}

Carludovica palmata Ruiz \& Pav. (Figura 1, No. 2)

Granos asimétricos, apolares, monoporados, oblados, ámbito

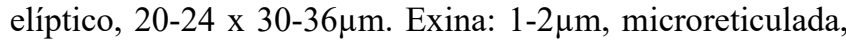
granulada; retículo heterobrocado simplicolumelado. Poros circulares: 6-9 9 m. M.E.: ICN 6083.

\section{CYPERACEAE}

Rhynchospora barbata (Vahl) Kunth (Figura 1S, No. 4)

Granos asimétricos, apolares, inaberturados, piriformes, oblados a suboblados, ámbito circular, 16-26 x 25-30 $\mu \mathrm{m}$. Exina: $<1 \mu \mathrm{m}$, areolada y verrugada. M.E.: ICN 3454 .

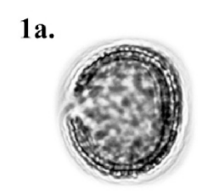

$1 \mathrm{~b}$.
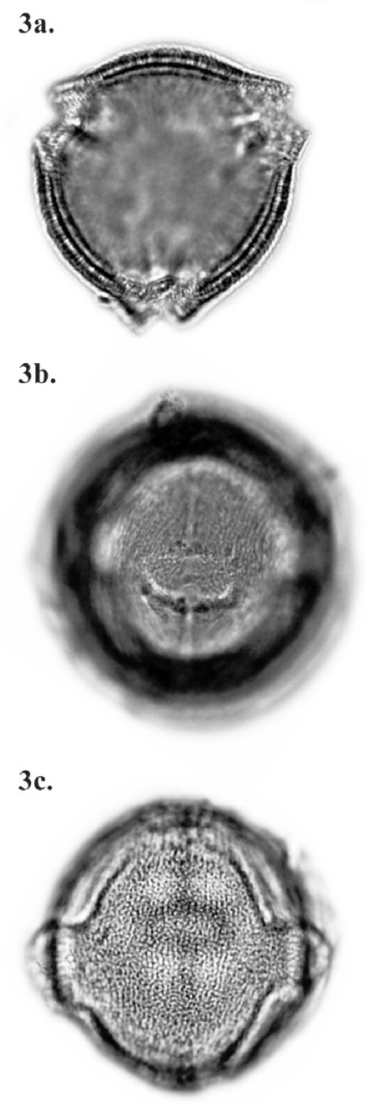

1c.

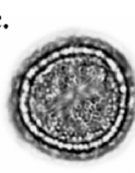

4a.

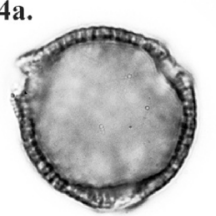

$4 b$.

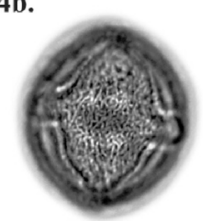

4c.

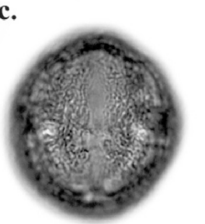

7 a.

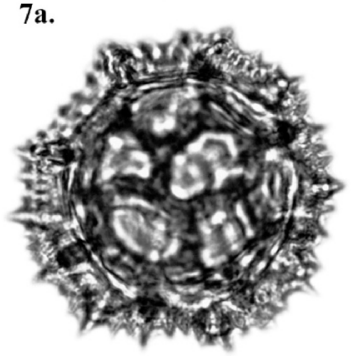

$2 b$.

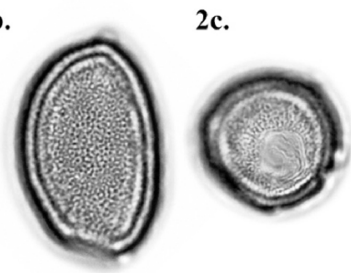

$6 a$.

$5 a$.

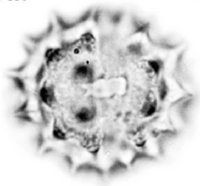

$5 b$.

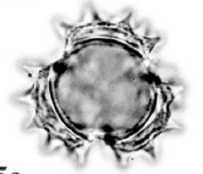

$5 c$.

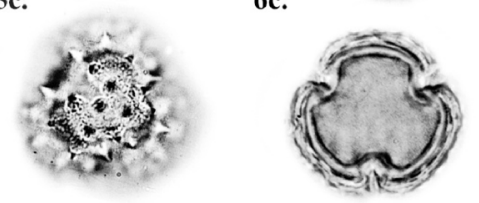

$6 b$.
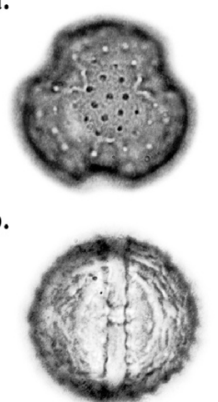

$7 b$.

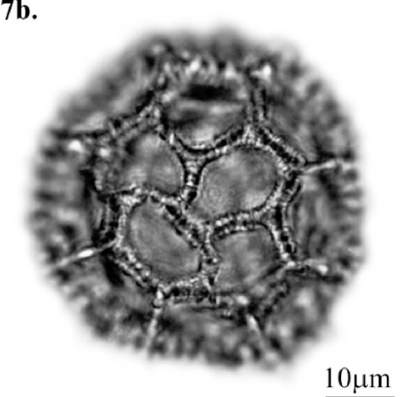

Figura 1. ARECACEAE: 1. Dictyocaryum lamarckianum. CYCLANTHACEAE: 2. Carludovica palmata. ANACARDIACEAE: 3. Anacardium excelsum. 4. Astronium graveolens. ASTERACEAE: 5. Austroeupatorium inulifolium. 6. Critonia morifolia. 7. Eirmocephala brachiata. 
Scleria mitis P.J. Bergius (Figura 1S, No. 5)

Granos asimétricos, apolares, monoporados, forma esferoidal o trapezoidal, ámbito circular, $38-52 \mu \mathrm{m}$. Exina: $1-1,5 \mu \mathrm{m}$, columelada y areolada. Poro con borde irregular $7-20 \mu \mathrm{m}$. M.E.: ICN 16279.

\section{POACEAE}

Brachiaria brizantha (Hochst. ex A. Rich.) Stapf (Figura 1S, No. 6)

Granos asimétricos, heteropolares, monoporados, esferoidales, ámbito circular, 59-77 $\mu \mathrm{m}$. Exina: 1-3 $\mu \mathrm{m}$, escabrada-areolada. Poro circular anulado de 1-7 $\mu \mathrm{m}$. M.E.: LABUN 922.

Holcus lanatus L. (Figura 1S, No. 7)

Granos asimétricos, heteropolares, monoporados, esferoidales, ámbito circular, $30-40 \mu \mathrm{m}$. Exina: $1-2 \mu \mathrm{m}$, escabrada. Poro circular anulado de 2-5 $\mu \mathrm{m}$. M.E.: LABUN 519.

Melinis minutiflora P.Beauv. (Figura 2S, https://www. raccefyn.co/index.php/raccefyn/article/view/61/669; No. 8)

Granos asimétricos, heteropolares, monoporados, esferoidales, ámbito circular, 71-102 $\mu \mathrm{m}$. Exina: 1-2 $\mu \mathrm{m}$, escabrada-areolada. Poro circular anulado de 5-7 $\mu \mathrm{m}$. M.E.: LABUN 923.

Pennisetum purpureum Schumach. (Figura 2S, No. 9)

Granos asimétricos, heteropolares, monoporados, esferoidales, ámbito circular, 62-90 $\mu \mathrm{m}$. Exina: 1-3 $\mu \mathrm{m}$, escabrada-areolada. Poro circular anulado de $2-7 \mu \mathrm{m}$. M.E.: LABUN 748.

Zea mays L. (Figura 2S, No. 10)

Granos asimétricos, heteropolares, monoporados, esferoida-

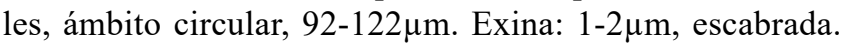

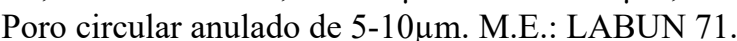

\section{CLASE MAGNOLIOPSIDA O DICOTILEDONEAS}

\section{ACTINIDACEAE}

\section{Saurauia yasicae Loes. (Figura 2S, No. 11)}

Granos radiosimétricos, apolares, tricolporados?, esferoida-

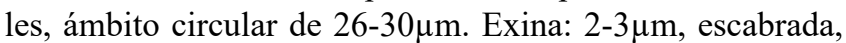
nexina más ancha que la sexina. Poros lalongados (3-6 x 1-6 $\mu \mathrm{m})$. Colporos generalmente inconspicuos y estrechos de $<1 \mu \mathrm{m}$. M.E.: LABUN 2091.

\section{AMARANTHACEAE}

Iresine diffusa Humb. \& Bonpl. ex Willd. (Figura 2S, No. 12)

Granos asimétricos, apolares, esferoidales, periporados (1622 poros por grano); $14-18 \mu \mathrm{m}$ de diámetro. Exina: 1,5-2 $\mu \mathrm{m}$,

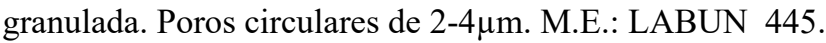

\section{ANACARDIACEAE}

Anacardium excelsum (Bertero \& Balb. Ex Kunth) Skeels (Figura 1, No. 3)

Granos radiosimétricos, isopolares, tricolporados, subprolados a esferoidales, ámbito circular; DE: 40-48, DP: 42-55 $\mu \mathrm{m}$. Exina: $3-4 \mu \mathrm{m}$, reticulada y estriada. Retículo homobrocado, simplicolumelado, lúmen de $<1 \mu \mathrm{m}$; poro irregular de 4-11 $\mu \mathrm{m}$; sexina más delgada en los bordes del poro; colpos tan largos como los granos, de 1-2 $\mu \mathrm{m}$ de ancho; lado apocolpio de 10$13 \mu \mathrm{m}$. M.E.: LABUN 451.

\section{Astronium graveolens Jacq. (Figura 1, No. 4)}

Granos radiosimétricos, isopolares, tricolporados, subprolados a esferoidales, ámbito circular o hexagonal; DE: 24-30, DP: 30-39 $\mu \mathrm{m}$. Exina: $1,5-3 \mu \mathrm{m}$, reticulada y estriada; retículo heterobrocado, más pequeño hacia los colpos, elongado y simplicolumelado, lúmen de $<1-2 \mu \mathrm{m}$; poros lalongados (6$13 \times 2-5 \mu \mathrm{m}$ ) con bordes engrosados; colpos tan largos como

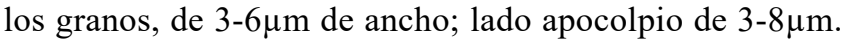
M.E.: LABUN 1811.

Mangifera indica L. (Figura 3S, https://www.raccefyn.co/ index.php/raccefyn/article/view/61/670; No. 13)

Granos radiosimétricos, isopolares, tricolporados, proladoesferoidales a subprolados, ámbito circular, DE: 28-35, DP: $34-42 \mu \mathrm{m}$. Exina: $2-3 \mu \mathrm{m}$, téctum reticulado-estriado, infratéctum columelado; muro y lúmen de $<1-1 \mu \mathrm{m}$. Poro lalongados y sobresalientes $(5-11$ x 3-8 $\mu \mathrm{m})$. Colpos tan largos como los granos, de $<1-2 \mu \mathrm{m}$ de ancho. M.E.: LABUN 356.

\section{AQUIFOLIACEAE}

\section{Ilex kunthiana Triana (Figura 3S, No. 14)}

Granos radiosimétricos, isopolares, tricolporados, suboblados a prolados, ámbito trilobado, DE: $29-40$, DP: $34-42 \mu \mathrm{m}$. Exina: $3-6 \mu \mathrm{m}$, clavada; clavas de $1-3 \mu \mathrm{m}$ de ancho y $2-3 \mu \mathrm{m}$ de largo, distancia entre clavas de $<1-1 \mu \mathrm{m}$. Poros lalongados (4-11 $\mathrm{x}<1-6 \mu \mathrm{m})$. Colpos tan largos como los granos, de 4-11 $\mu \mathrm{m}$ de ancho. M.E.: LABUN 1813.

\section{ARALIACEAE}

Oreopanax capitatus (Jacq.) Decne. \& Planch. (Figura 3S, No. 15)

Granos radiosimétricos, isopolares, tricolporados, prolados esferoidales a prolados, ámbito triangular recto o convexo; DE: 18-26, DP: 23-28 $\mu \mathrm{m}$. Exina: 1-2 $\mu \mathrm{m}$ de grosor, reticulada. Retículo heterobrocado más pequeño hacia los colpos, muro de $<1 \mu \mathrm{m}$, lúmen de $<1-1,5 \mu \mathrm{m}$. Poros lalongados $\mathrm{y}$ sobresalientes $(5-7 \times 2-5 \mu \mathrm{m})$. Colpos con margo grueso, tan largos como los granos, de $1 \mu \mathrm{m}$ de ancho. Lado apocolpio

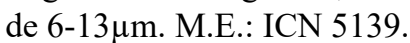

\section{ASTERACEAE}

Acmella ciliata (Kunth) Cass. (Figura 3S, No. 16) 


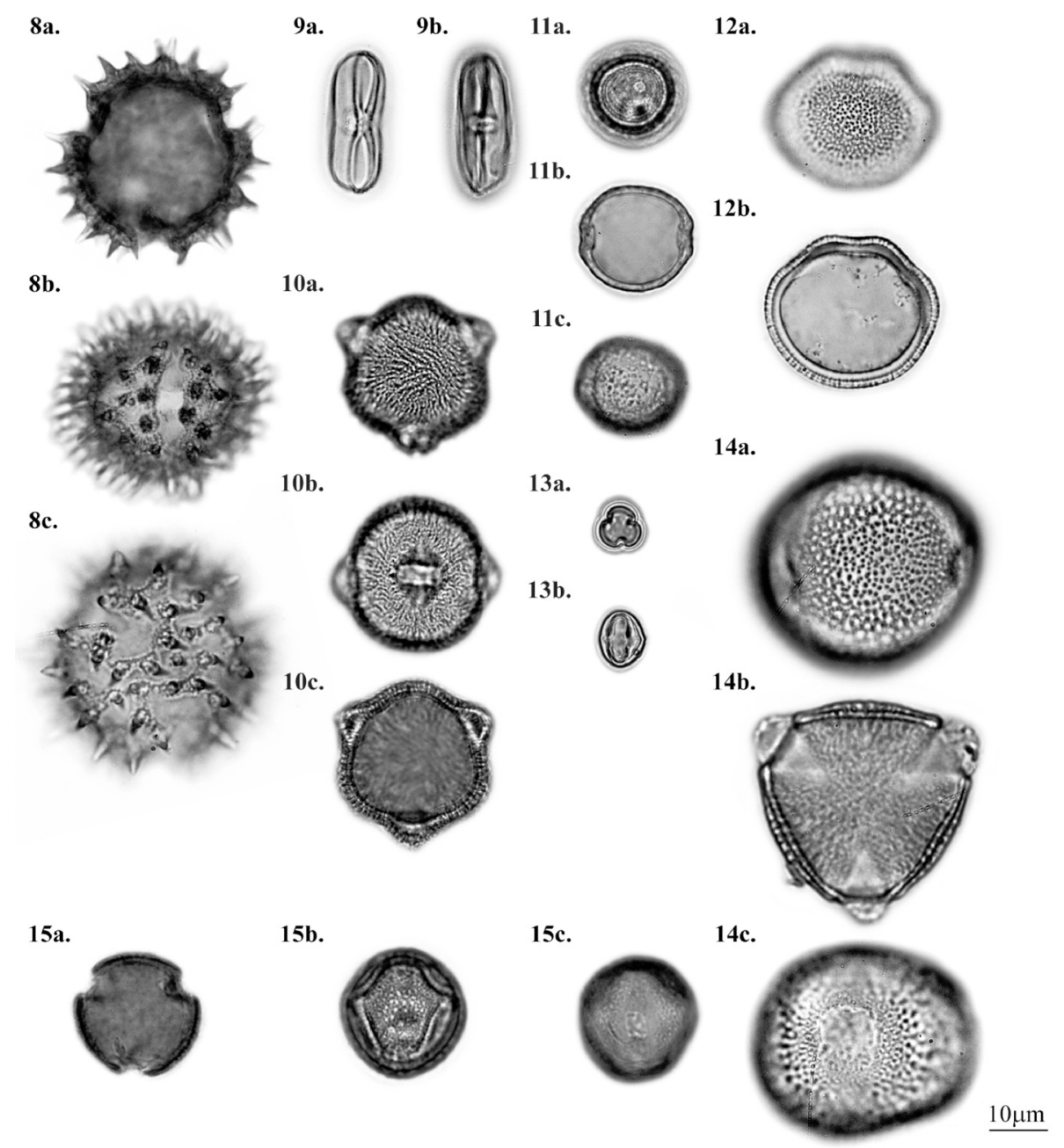

Figura 2. ASTERACEAE: 8. Vernonanthura patens. BEGONIACEAE: 9. Begonia guaduensis. BURSERACEAE: 10. Bursera simaruba. CANNABACEAE: 11. Trema micrantha. CHLORANTHACEAE: 12. Hedyosmum racemosum. CUNONIACEAE: 13. Weinmannia pinnata. DILLENIACEAE: 14. Davilla kunthii. 15. Doliocarpus dentatus.

Granos radiosimétricos, isopolares, tricolporados o tetracolporados, oblado-esferoidales a prolado-esferoidales, ámbito circular; DE: 27-42, DP: $31-42 \mu \mathrm{m}$ excluidas las espinas. Exina: $9-11 \mu \mathrm{m}$, equinada y columelada; espinas puntiagudas, de tamaño variable $(6-8 \mu \mathrm{m}$ de ancho en la base y $5-12 \mu \mathrm{m}$ de largo), a veces más anchas que largas. Poros lalongados (7$13 \times 1-3 \mu \mathrm{m}$ ). Colpos tan largos como los granos, de 1-3um de ancho. M.E.: LABUN 697.

Austroeupatorium inulifolium (Kunth) R.M. King \& H. Rob. (Figura 1, No. 5)

Granos radiosimétricos, isopolares, tricolporados, suboblados a esferoidales, ámbito circular; DE: 19-27, DP: $22-26 \mu \mathrm{m}$ excluidas las espinas. Exina: 2-6 $\mathrm{m}$, equinada y escabrada, espinas de $2-4 \mu \mathrm{m}$. Poros lalongados, a veces con constricción en el medio (6-7 x 1-3 $\mu \mathrm{m})$. Colpos tan largos como los granos, de 3-5 $\mu \mathrm{m}$ de ancho. M.E.: LABUN 1673.

\section{Baccharis trinervis Pers. (Figura 3S, No. 17)}

Granos radiosimétricos, isopolares, tricolporados, suboblados a esferoidales, ámbito circular; DE: 19-24, DP: $18-22 \mu$ excluidas las espinas. Exina: $5-7 \mu \mathrm{m}$, equinada y escabrada, espinas de $3-4 \mu \mathrm{m}$ de ancho en la base y $3-5 \mu \mathrm{m}$ de largo. Poros lalongados $(4-7 \times 3-5 \mu \mathrm{m})$. Colpos tan largos como los granos, de 2-4 $\mu \mathrm{m}$ de ancho. M.E.: LABUN 471.

Bidens pilosa L. (Figura 3S, No. 18)

Granos radiosimétricos, isopolares, tricolporados, suboblados a oblado-esferoidales, ámbito circular; DE: 33-39, DP: 32$35 \mu \mathrm{m}$ excluidas las espinas. Exina: $8-10 \mu \mathrm{m}$, equinada, espinas puntiagudas de base ancha y granulada de $6-8 \mu \mathrm{m}$. Poros lalongados $(8-14 \times 3-5 \mu \mathrm{m})$. Colpos tan largos como los granos, de 2-5 $\mu \mathrm{m}$ de ancho. M.E.: LABUN 492.

Clibadium surinamense L. (Figura 3S, No. 19) 

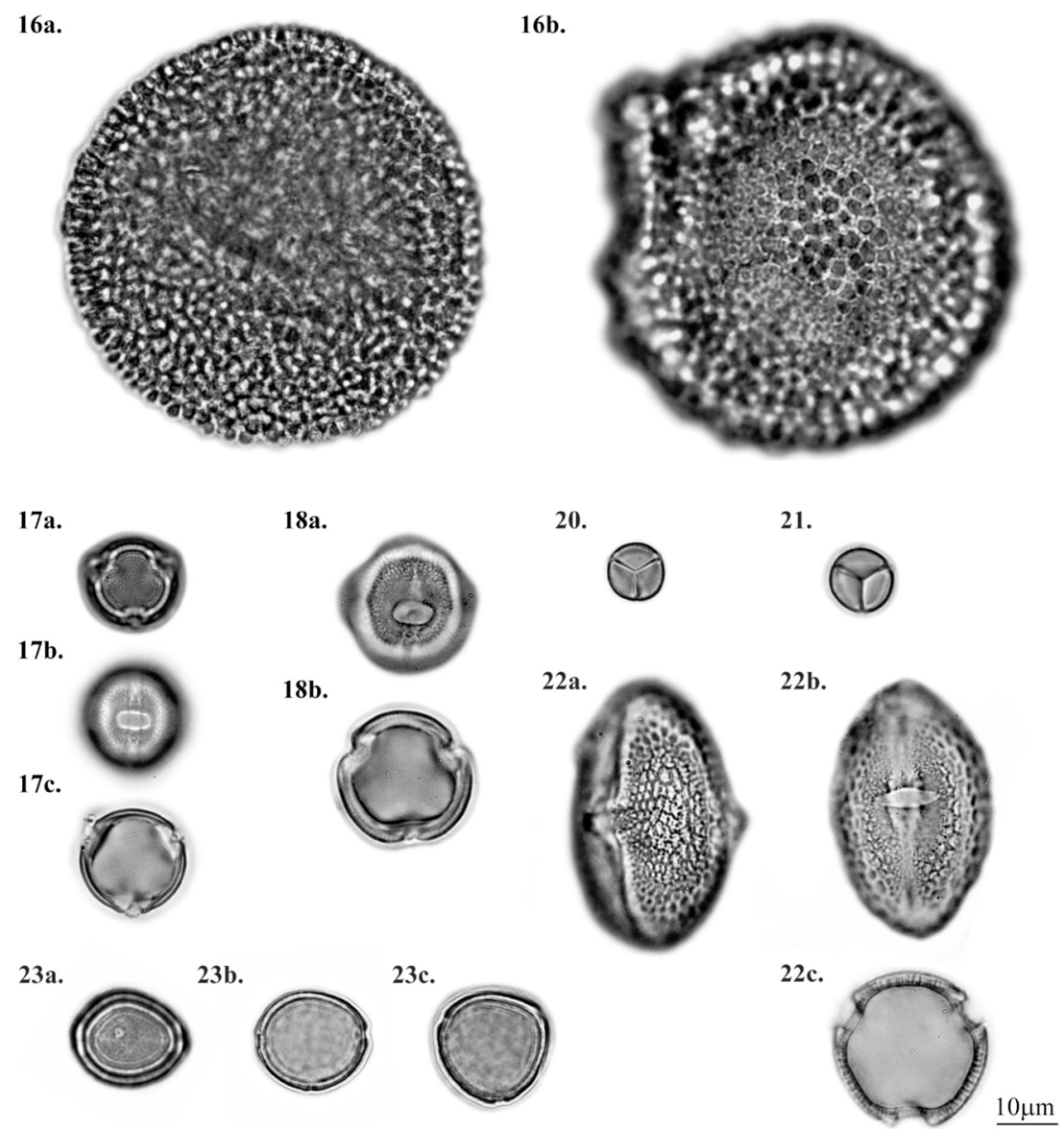

Figura 3. 16. Croton hirtus. FABACEAE (FABOIDAE): 17. Gliricidia sepium. 18. Platymiscium pinnatum. FABACEAE (MIMOSOIDAE): 20. Mimosa albida. 21. Mimosa pudica. MALVACEAE (GREWIOIDEAE): 22. Heliocarpus americanus. MORACEAE: 23. Poulsenia armata.

Granos radiosimétricos, isopolares, tricolporados, suboblados a prolado-esferoidales, ámbito circular; DE: 27-34, DP: 27-32 $\mu \mathrm{m}$ excluidas las espinas. Exina: $5-9 \mu \mathrm{m}$ de grosor, equinada y escabrada. Espinas puntiagudas con base granulada, de $4-7 \mu \mathrm{m}$ de ancho y $5-7 \mu \mathrm{m}$ de largo. Poros lalongados, a veces con constricción en el medio (7-13 x 3-5 $\mu \mathrm{m})$. Colpos tan largos como los granos, de $3-5 \mu \mathrm{m}$ de ancho. M.E.: LABUN 761.

Critonia morifolia (Mill.) R.M.King \& H.Rob. (Figura 1, No. 6)

Granos radiosimétricos, isopolares, tricolporados, esferoidales, ámbito circular o trilobado; DE: 19-25, DP: 22-29 $\mu \mathrm{m}$. Exina: 3-4 $\mu \mathrm{m}$, microequinada y escabrada. Poros lalongados (5-7 x 1-2 $\mu \mathrm{m})$. Colpos tan largos como los granos, de $1-5 \mu \mathrm{m}$ de ancho. M.E.: LABUN 448.

Eirmocephala brachiata (Benth.) H.Rob. (Figura 1, No. 7)

Granos asimétricos, apolares, periporados, esferoidales, ámbito circular, $40-53 \mu \mathrm{m}$ de diámetro excluidas las espinas. Exina:
6-9 $9 \mathrm{~m}$, equinada y lofada, crestas de $3-4 \mu \mathrm{m}$ de ancho, 12 a 23 lacunas por grano (10-18 $\mu \mathrm{m}$ de diámetro), espinas de 1,5$2 \mu \mathrm{m}$ de ancho en la base y $2-3,5 \mu \mathrm{m}$ de largo. Poros irregulares que pueden ser tantos y tan grandes como las lacunas. M.E.: LABUN 1437.

Emilia sonchifolia (L.) DC. ex DC. (Figura 4S, https://www.raccefyn.co/index.php/raccefyn/article/ view/61/671; No. 20)

Granos polimórficos, simétricos o asimétricos, isopolares heteropolares o apolares, tricolporados, tetracolporados, pericolpados, a veces sincolpados, esferoidales, ámbito circular o cuadrangular; $38-45 \mu \mathrm{m}$ de diámetro excluidas las espinas. Exina: $7-8 \mu \mathrm{m}$, equinada y escabrada, espinas contiguas de

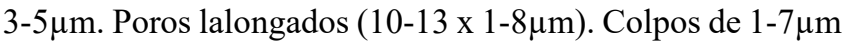
de ancho; aveces se presentan colpos latitudinales en el área polar o ecuatorial. M.E.: LABUN 474.

Hypochaeris radicata L. (Figura 4S, No. 21)

Granos radiosimétricos, isopolares, tricolporados, suboblados a oblado-esferoidales, ámbito hexagonal; DE: 32-40, DP: 


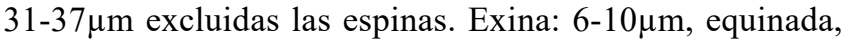
lofada y escabrada, crestas de $4-5 \mu \mathrm{m}$ de ancho con espacios interlacunares, lacunas de $7-17 \mu \mathrm{m}$, espinas de $1-2 \mu \mathrm{m}$. Poros lalongados, a veces con constricción en el medio (10-12 x 4-5 $\mu \mathrm{m})$. M.E.: LABUN 557.

\section{Lepidaploa canescens (Kunth) H. Rob. Figura 4S, No. 22)}

Granos radiosimétricos, isopolares, tricolporados, obladoesferoidales a esferoidales, ámbito circular; DE: 35-40, DP: $29-38 \mu \mathrm{m}$ excluidas las espinas. Exina: $5-7 \mu \mathrm{m}$, equinada y lofada; crestas granuladas de $4-5 \mu \mathrm{m}$ de ancho, lacunas de $1-8 \mu \mathrm{m}$, espinas piramidales y puntiagudas de $2-3 \mu \mathrm{m}$ de ancho en la base y $4-5 \mu \mathrm{m}$ de largo. Poros lalongados con constricción en el medio (5-7 x 4-5 $\mu \mathrm{m})$. Colpos a manera de fenestras elongadas paralelas al eje polar. M.E.: LABUN 786.

Mikania micrantha Kunth (Figura 4S, No. 23)
Granos radiosimétricos, isopolares, tricolporados, obladoesferoidales a esferoidales, ámbito circular; DE: 22-23, DP: 21-23 $\mu \mathrm{m}$ excluidas las espinas. Exina: $8-10 \mu \mathrm{m}$, equinada y escabrada, espinas puntiagudas de base ancha y columelada, de $5-6 \mu \mathrm{m}$ de ancho en la base y $6-7 \mu \mathrm{m}$ de largo. Poros lalongados, a veces con constricción en el medio (8-10 x $1-4 \mu \mathrm{m})$. Colpos tan largos como los granos, de $4-5 \mu \mathrm{m}$ de ancho. M.E.: LABUN 1580.

Neurolaena lobata (L.) R.Br. ex Cass. (Figura 4S, No. 24)

Granos radiosimétricos, isopolares, tricolporados, obladoesferoidales, ámbito circular; DE: 25-30, DP: 23-25 $\mu \mathrm{m}$ excluidas las espinas. Exina: $4-8 \mu \mathrm{m}$ de grosor, equinada y escabrada; espinas de tamaño variable que van desde cortas y achatadas a manera de verrugas hasta grandes y puntiagudas $(3-6 \mu \mathrm{m})$. Poros lalongados y angostos $(7-10 \times 1-2 \mu \mathrm{m})$.
19.

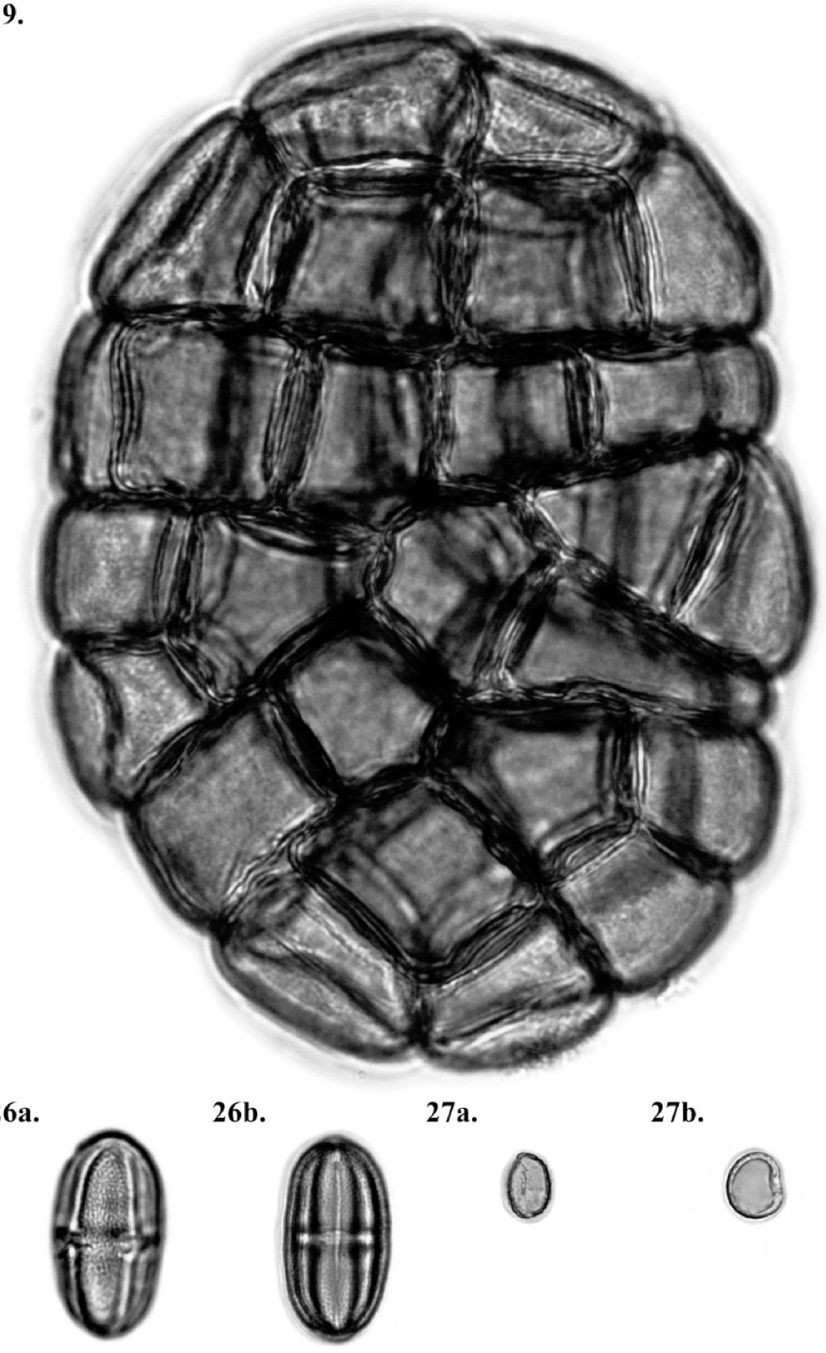

$24 a$.

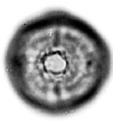

24b.

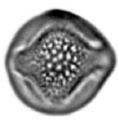

24c.

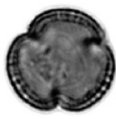

25a.

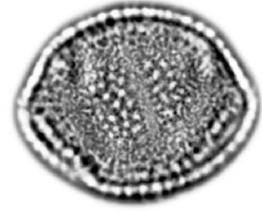

25b.

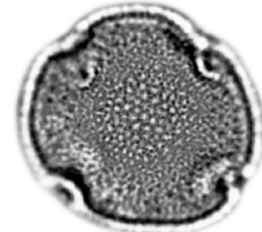

25c.

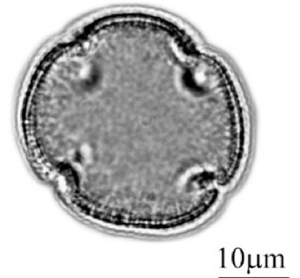

Figura 4. FABACEAE (MIMOSOIDAE): 19. Inga oerstediana. MUNTINGIACEAE: 24. Muntingia calabura. OLEACEAE: 25. Fraxinus chinensis. PHYLLANTHACEAE: 26. Hieronyma fendleri. PIPERACEAE: 27. Piper aduncum. 
28a.

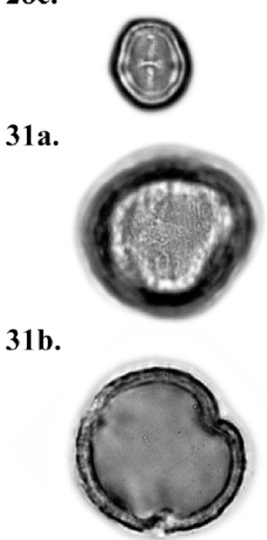

31c.

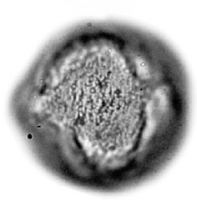

$35 a$. $35 b$.
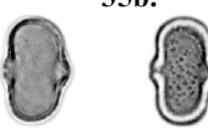

$35 c$.

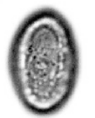

29a.

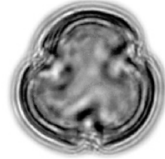

29b.

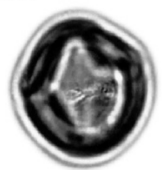

$32 a$.

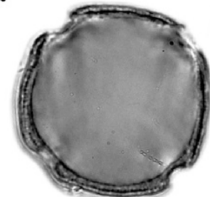

$32 b$.

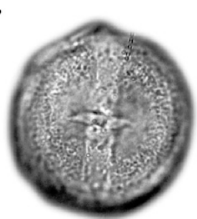

$32 c$.

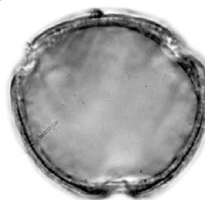

$32 d$.

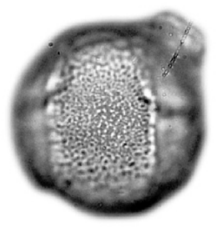

30a.

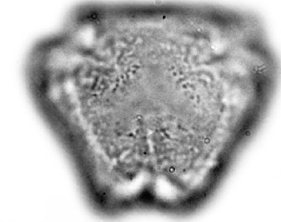

30c.

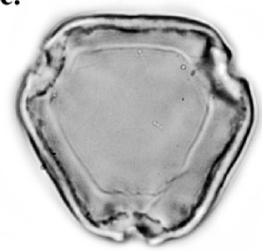

$33 a$.

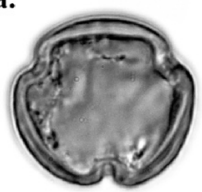

33b.

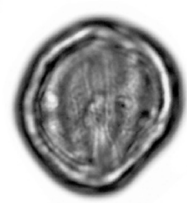

33c.

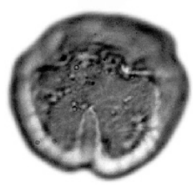

36a.

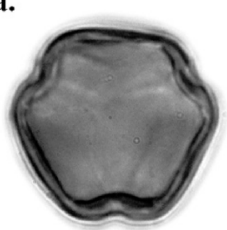

30b.

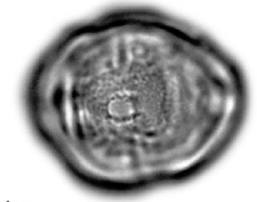

$34 a$.

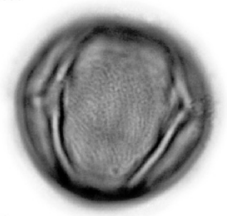

34b.

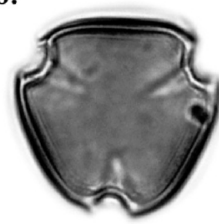

$34 c$.

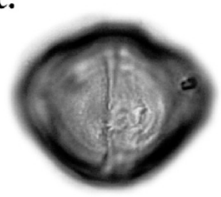

$36 b$.

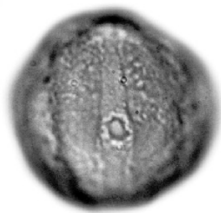

$36 c$.

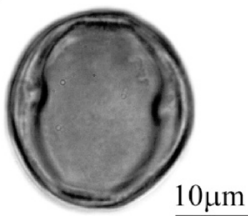

Figura 5. PRIMULACEAE: 28. Ardisia guianensis. 29. Cybianthus nevadensis. RHAMNACEAE: 30. Gouania polygama. ROSACEAE: 31. Rubus urticifolius. RUBIACEAE: 32. Coffea arabica. SAPINDACEAE: 33. Melicoccus bijugatus. 34. Melicoccus oliviformis. URTICACEAE: 35. Cecropia peltata. VITACEAE: 36.Vitis tiliifolia.

Colpos tan largos como los granos, de 2-4 $\mu \mathrm{m}$ de ancho. Lado apocolpio de 10-12 $\mu \mathrm{m}$. M.E.: ICN 2861.

Tithonia diversifolia (Hemsl.) A.Gray (Figura 5S, https:// www.raccefyn.co/index.php/raccefyn/article/view/61/672; No. 25)

Granos radiosimétricos, isopolares, tricolporados, esféricos, ámbito circular; $35-50 \mu \mathrm{m}$ excluidas las espinas. Exina: $7-14 \mu \mathrm{m}$, equinada y granulada; espinas de forma y tamaño muy variable, puntiagudas o de punta redonda a manera de verrugas $(2-11 \mu \mathrm{m})$; poros inconspicuos, colpos angostos de 1-3 $\mu \mathrm{m}$ de ancho. M.E.: LABUN 500.
Vernonanthura patens (Kunth) H.Rob. (Figura 2, No. 8)

Granos simétricos, isopolares, tricolporados, suboblados a oblado-esferoidales, ámbito circular; DE: 35-39, DP: 30$35 \mu \mathrm{m}$ excluidas las espinas. Exina: $2-5 \mu \mathrm{m}$ de grosor, equinada, lofada, crestas y lacunas de tamaño y forma variable, espinas de $2-3 \mu \mathrm{m}$ de ancho en la base y 3,5-5 $\mu \mathrm{m}$ de largo; poros lalongados, a veces con constricción en el medio (1014 x 3-5 $\mu \mathrm{m})$; colpos tan largos como los granos, de $4-7 \mu \mathrm{m}$ de ancho. M.E.: LABUN 1821.

\section{BALSAMINACEAE}

Impatiens walleriana Hook.f. (Figura 5S, No. 26) 
Granos con simetría bilateral, isopolares, tetracolpados, oblados, ámbito cuadrangular; DE1: 57-66, DE2: 34-39, DP:

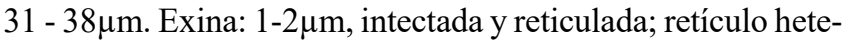
robrocado más pequeño hacia los colpos, duplicolumelado,

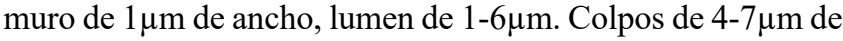
largo y 1-2 $\mu \mathrm{m}$ de ancho. M.E.: LABUN 120.

\section{BEGONIACEAE}

Begonia guaduensis Kunth (Figura 2, No. 9)

Granos con radiosimétricos, isopolares, tricolporados, prolados, ámbito trilobado; DE: 8-10, DP: $22-28 \mu \mathrm{m}$. Exina: $<1 \mu \mathrm{m}$,

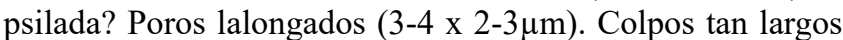
como los granos, de $<1 \mu \mathrm{m}$ de ancho. M.E.: LABUN 1061.

\section{BIGNONIACEAE}

\section{Tabebuia rosea (Bertol.) DC. (Figura 5S, No. 27)}

Granos radiosimétricos, isopolares, tricolporados, suboblados a prolados, ámbito triangular convexo, DE: 29-53, DP: 37-56 $\mu \mathrm{m}$. Exina: $2-4 \mu \mathrm{m}$ de grosor, microreticulada, homobrocada

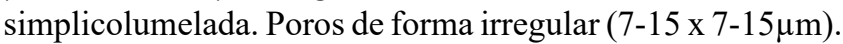
Colpos tan largos como los granos, de 3-14 $\mu \mathrm{m}$ de ancho. Lado apocolpio de 5-11 $\mu$ m. M.E.: LABUN 499.

\section{BORAGINACEAE}

Cordia alba (Jacq.) Roem. \& Schult. (Figura 6S, https:// www.raccefyn.co/index.php/raccefyn/article/view/61/673; No. 28)

Granos radiosimétricos, isopolares, tricolporados, peroblados a oblado-esferoidales, ámbito trilobado o triangular convexo; DE: 42-51, DP: $23-40 \mu \mathrm{m}$. Exina: $2-3 \mu \mathrm{m}$, granulada. Poros grandes e irregulares $(10-15 \times 8-16 \mu \mathrm{m})$. Colpos tan largos como los granos, con borde irregular y restos de membrana ectexínica $(10-15 \mu \mathrm{m}$ de ancho). Lado apocolpio de 10$14 \mu$ m. M.E.: LABUN 508.

Cordia alliodora (Ruiz \& Pav.) Oken (Figura 6S, No. 29)

Granos radiosimétricos, isopolares, tricolporados, suboblados a prolado-esferoidales, ámbito circular o trilobado, DE: 4760, DP: $45-62 \mu \mathrm{m}$. Exina: $3-4 \mu \mathrm{m}$, equinada y escabrada;

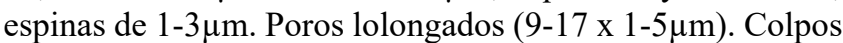
cortos y angostos (20-40 $\mu \mathrm{m}$ de largo y $1-2 \mu \mathrm{m}$ de ancho), con costa gruesa $(5-7 \mu \mathrm{m})$. M.E.: LABUN 981.

Cordia spinescens L. (Figura 6S, No. 30)

Granos radiosimétricos, isopolares, triporados, esferoidales, ámbito circular, $63-72 \mu \mathrm{m}$ de diametro. Exina: 5-9 $\mu \mathrm{m}$, reticulada; retículo homobrocado, simplicolumelado, muro de $1,5-3 \mu \mathrm{m}$ de ancho, lumen de $2-8 \mu \mathrm{m}$. Poros circulares (8$10 \mu \mathrm{m})$. M.E.: LABUN 1270.

\section{BURSERACEAE}

Bursera simaruba (L.) Sarg. (Figura 2, No. 10)
Granos radiosimétricos, isopolares, tricolporados, obladoesferoidales a prolado- esferoidales, ámbito circular; DE: 24-33, DP: $26-32 \mu \mathrm{m}$. Exina: $1,5-2 \mu \mathrm{m}$, microreticulada y estriada. Poros lalongados y costados $(8-11 \times 2-4 \mu \mathrm{m})$. Colpos inconspicuos. M.E.: LABUN SA928M.

\section{CANNABACEAE}

Celtis iguanaea (Jacq.) Sarg. (Figura 7S, https://www. raccefyn.co/index.php/raccefyn/article/view/61/674; No. 31)

Granos radiosimétricos, isopolares, triporados o tetraporados, suboblados a oblados esferoidales, ámbito circular, DE: 2225, DP: $18-23 \mu \mathrm{m}$. Exina: $1-1,5 \mu \mathrm{m}$ de grosor, escabrada. Poros circulares y anulados $(2-3 \mu \mathrm{m})$. M.E.: LABUN 2088.

\section{Trema micrantha (L.) Blume (Figura 2, No. 11)}

Granos con simetría bilateral, isopolares, diporados, suboblados a esferoidales, ámbito elíptico; DE: 17-24, DP:

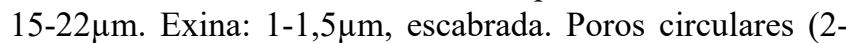
$3 \mu \mathrm{m})$, vestibulados. M.E.: LABUN 489.

\section{CHLORANTHACEAE}

Hedyosmum racemosum (Ruiz \& Pav.) G.Don (Figura 2, No. 12)

Granos asimétricos, heteropolares, inaberturados, esferoidales, ámbito circular, 24-45 $\mu \mathrm{m}$ de diámetro. Exina: 2,5$4 \mu \mathrm{m}$, granulada; generalmente en un lado del grano se presenta un ondulamiento y engrosamiento de la nexina. M.E.: LABUN 836.

\section{CHRYSOBALANACEAE}

Chrysobalanus icaco L. (Figura 7S, No. 32)

Granos radiosimétricos, isopolares, tricolporados, oblados a suboblados, ámbito triangular recto o concavo, DE: 45-50, DP: $30-37 \mu \mathrm{m}$. Exina: $3-5 \mu \mathrm{m}$, escabrada y fosulada. Poros grandes lalongados o de forma irregular $(15-20 \times 10-20 \mu \mathrm{m})$. Colpos tan largos como los granos, de $10-20 \mu \mathrm{m}$ de ancho y con margo grueso de 2-3 $\mu \mathrm{m}$. Lado apocolpio de $10-12 \mu \mathrm{m}$. M.E.: LABUN 2093.

\section{CLUSIACEAE}

Clusia multiflora Kunth (Figura 7S, No. 33)

Granos radiosimétricos, isopolares, tricolporados, suboblados a subprolados, ámbito circular; DE: 26-30, DP: 26-33 $\mu \mathrm{m}$. Exina gruesa: $2-3 \mu \mathrm{m}$, fosulada y perforada. Poros lalongados inconspicuos y anulados $(3-5 \times 1 \mu \mathrm{m})$. Colpos tan largos como

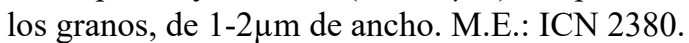

\section{CONVOLVULACEAE}

Ipomoea batatas (L.) Lam. (Figura 7S, No. 34)

Granos asimétricos, apolares, periporados (80 poros apro- 
ximadamente), esferoidales, ámbito circular, $112-142 \mu$ de diámetro. Exina: 16-26 $\mu \mathrm{m}$, equinada y granulada en el interporium y escabrada en los bordes de los poros. Espinas de $5-7 \mu \mathrm{m}$ de ancho y $10-14 \mu \mathrm{m}$ de largo. Poros circulares (4$11 \mu \mathrm{m})$. Distancia entre poros: 8-10 $\mu \mathrm{m}$. M.E.: LABUN 42.

Merremia umbellata (L.) Hallier f. (Figura 8S, https:// www.raccefyn.co/index.php/raccefyn/article/view/61/675; No. 35)

Granos radiosimétricos, isopolares, estefanocolpados (seis colpos), oblado-esferoidales a prolado-esferoidales, ámbito elíptico; DE: 76-106, DP: 76-95 $\mu \mathrm{m}$. Exina: 4-7 $\mu \mathrm{m}$, baculada. Colpos tan largos como los granos, de $1-15 \mu \mathrm{m}$ de ancho. M.E.: LABUN 433.

\section{CUNONIACEAE}

Weinmannia pinnata L. (Figura 2, No. 13)

Granos radiosimétricos, isopolares, tricolporados, esferoidales a prolados, ámbito circular o trilobado; DE: 8-10, DP: 10-12 $\mu \mathrm{m}$. Exina: $<1 \mu \mathrm{m}$, microreticulada. Poros inconspicuos (1-2 $\mu \mathrm{m})$. Colpos tan largos como los granos, de $<1-1 \mu \mathrm{m}$ de ancho. M.E.: ICN 4822.

\section{DILLENIACEAE}

\section{Davilla kunthii A.St.-Hil. (Figura 2, No. 14)}

Granos radiosimétricos, isopolares, tricolporados, suboblados a esferoidales, ámbito triangular convexo, 30-45 $\mu \mathrm{m}$ de diámetro. Exina: $2-4 \mu \mathrm{m}$ de grosor, reticulada; retículo heterobrocado, más pequeño hacia los colpos, simplicolumelado, muro de $1 \mu \mathrm{m}$ de ancho, lumen de $1-4 \mu \mathrm{m}$. Poros circulares con restos de membrana ectecxínica $(8-11 \mu \mathrm{m})$. Colpos con margo, tan largos como los granos, de $8-12 \mu \mathrm{m}$ de ancho. Lado apocolpio

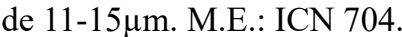

Doliocarpus dentatus (Aubl.) Standl. (Figura 2, No. 15)

Granos radiosimétricos, isopolares, tricolporados, obladoesferoidales a prolado-esferoidales, ámbito circular o trilobado,

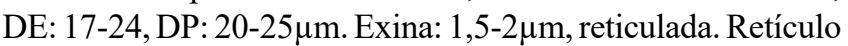
heterobrocado, simplicolumelado y duplicolumelado, más pequeño hacia los colpos, muro de $<1-1 \mu \mathrm{m}$, lúmen de $<1$ $2 \mu \mathrm{m}$. Poros circulares y con restos de membrana ectexínica

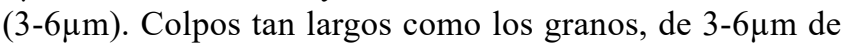
ancho. Lado apocolpio de 6-7 $\mu$ m. M.E.: LABUN 2094.

\section{ELAEOCARPACEAE}

\section{Sloanea multiflora H.Karst. (Figura 8S, No. 36)}

Granos radiosimétricos, isopolares, tricolporados, suboblados a prolados, ámbito circular, DE: 16-23, DP: 17-24 $\mu \mathrm{m}$. Exina: $1-1,5 \mu \mathrm{m}$, microreticulada. Poros lalongados incons-

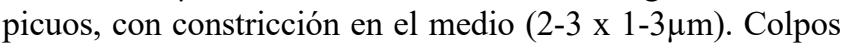
tan largos como los granos, de $1-3 \mu \mathrm{m}$ de ancho. Lado

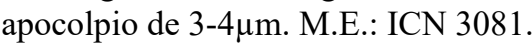

\section{ERYTHROXYLACEAE}

Erythroxylum novogranatense (D.Morris) Hieron. (Figura 8S, No. 37)

Granos radiosimétricos, isopolares, tricolporados, obladoesferoidales a prolado-esferoidales, ámbito circular o trilobado; DE: $34-50$, DP: $35-42 \mu \mathrm{m}$. Exina: $1-4 \mu \mathrm{m}$, reticulada. Retículo heterobrocado, más pequeño hacia los colpos y polos, simplicolumelado a multicolumelado, muro de $0,5-1,5 \mu \mathrm{m}$ de ancho, lumen de $<1-2 \mu \mathrm{m}$. Poros lalongados (8-14 x 3-8 $\mu \mathrm{m})$. Colpos costados, tan largos como los granos, de $3-7 \mu \mathrm{m}$ de ancho. Lado apocolpio de 6-9 $\mu$ m. M.E.: LABUN 410.

\section{ESCALLONIACEAE}

Escallonia pendula (Ruiz \& Pav.) Pers. (Figura 8S, No. 38)

Granos radiosimétricos, isopolares, tricolporados, obladoesferoidales a subprolados, ámbito trilobado; DE: 15-22, DP: 21-26 $\mu \mathrm{m}$. Exina: 1-2 $\mu \mathrm{m}$ escabrada. Poros de forma irregular

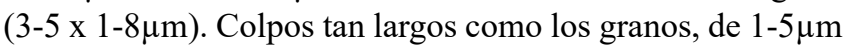
de ancho. Lado apocolpio de 4-8 $\mu$ m. M.E.: LABUN 1339.

\section{EUPHORBIACEAE}

Acalypha macrostachya Jacq. (Figura 9S, https:/www. raccefyn.co/index.php/raccefyn/article/view/61/676; No. 39)

Granos radiosimétricos, isopolares, tetracolporados o pentacolporados, suboblados a prolado-esferoidales, ámbito circular; DE: 19-23, DP: 17-21 $\mu \mathrm{m}$. Exina: 1-2 $\mu \mathrm{m}$, escabrada. Poros lalongados protuberantes, con fastigio y costa $(4-6 \mathrm{x}$ $1-3 \mu)$; colpos cortos, de 4-6 $\mu \mathrm{m}$ de largo y $1-3 \mu \mathrm{m}$ de ancho. M.E.: LABUN 901.

\section{Alchornea latifolia Sw. (Figura 9S, No. 40)}

Granos radiosimétricos, isopolares, tricolporados, suboblados a oblado-esferoidales, ámbito circular o trilobado; DE: 1923, DP: 16-21 $\mu \mathrm{m}$. Exina: 1-2 $\mu \mathrm{m}$ engrosada en los colporos, psilada o escabrada; poros lalongados con fastigio ocupado por columelas largas (3-4 x 1-2 $\mu \mathrm{m})$; colpos operculados, tan largos como los granos, de 2-4 $\mu \mathrm{m}$ de ancho. M.E.: LABUN 1824.

Croton hirtus L'Hér. (Figura 3, No. 16)

Granos radiosimétricos, apolares, inaberturados, ámbito circular; 60-80 $\mu \mathrm{m}$ de diámetro. Exina: $4-5 \mu \mathrm{m}$, intectada, clavada; clavas de 2-3 $\mu \mathrm{m}$ que forman rosetas. M.E.: LABUN 722.

Euphorbia hirta L. (Figura 9S, No. 41)

Granos radiosimétricos, isopolares, tricolporados, subprolados a prolados, ámbito trilobado, DE: 17-20, DP: $24-27 \mu \mathrm{m}$. Exina: $1,5-2 \mu \mathrm{m}$, más delgada hacia los polos, pilada. Poros lalongados $(6-9 \times 2-3 \mu \mathrm{m})$. Colpos tan largos como los granos, estrechos, de $<1-1 \mu \mathrm{m}$, con margo de $2-3 \mu \mathrm{m}$ de ancho conformado por columelas más pequeñas que en el resto de la exina. M.E.: LABUN 2103. 
Ricinus communis L. (Figura 9S, No. 42)

Granos radiosimétricos, isopolares, tricolporados, obladoesferoidales a esferoidales, ámbito circular; DE: 29-33, DP: 29-35 $\mu \mathrm{m}$. Exina: 1-2 $\mu \mathrm{m}$, microreticulada. Retículo homobro-

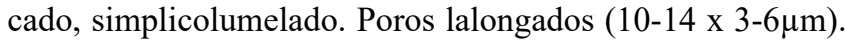
Colpos tan largos como los granos, angostos, de $1 \mu \mathrm{m}$ de

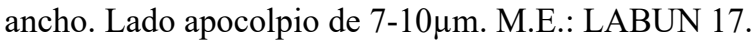

Sapium glandulosum (L.) Morong (Figura 9S, No. 43)

Granos radiosimétricos, isopolares, tricolporados, subprolados a prolados, ámbito circular o trilobado, DE: 33-40, DP: 45$55 \mu \mathrm{m}$. Exina: 1,5-3 $\mu \mathrm{m}$, pilada y perforada. Poros endexínicos, lalongados y costados $(15-25 \times 5-10 \mu \mathrm{m})$. Colpos tan largos como los granos, estrechos, de $1-3 \mu \mathrm{m}$ de ancho. M.E.: LABUN 2106.

\section{FABACEAE (Faboideae)}

Aeschynomene americana L. (Figura 9S, No. 44)

Granos radiosimétricos, isopolares, tricolporados sincolpados, suboblados a esferoidales, ámbito trilobado; DE: 17-24, DP: $12-22 \mu \mathrm{m}$. Exina: $1-2 \mu \mathrm{m}$, microreticulada; retículo homobrocado, simplicolumelado. Poros elípticos, lalongados o circulares $(4-7 \mu \mathrm{m})$. Colpos tan largos como los granos, de $2-5 \mu \mathrm{m}$ de ancho. M.E.: LABUN 598.

\section{Erythrina rubrinervia Kunth (Figura 9S, No. 45)}

Granos radiosimétricos, isopolares, triporados, oblados a suboblados, ámbito triangular cóncavo; DE: 43-50, DP: 31$40 \mu \mathrm{m}$. Exina: $3-4 \mu \mathrm{m}$, reticulada; retículo heterobrocado, más pequeño hacia los poros, muro de $\leq 1 \mu \mathrm{m}$, lumen de $1-8 \mu \mathrm{m}$ muy variable. Poros circulares cubiertos por membrana ectexínica $(5-10 \mu \mathrm{m})$. M.E.: LABUN 1169.

Gliricidia sepium (Jacq.) Kunth ex Walp. (Figura 3, No. 17)

Granos radiosimétricos, isopolares, tricolporados, proladoesferoidales, ámbito circular; DE: 16-20, DP: 17-20 $\mu \mathrm{m}$. Exina: $2 \mu \mathrm{m}$, microreticulada, homobrocada. Poros elípticos lalongados $(6-7 \times 3-5 \mu \mathrm{m})$; sexina adelgazada y nexina ligeramente engrosada en los bordes de los poros. Colpos tan largos como los granos, de 1-2 $\mu \mathrm{m}$ de ancho. Lado apocolpio de 6-8 $\mu$ m. M.E.: LABUN 419.

Platymiscium pinnatum (Jacq.) Dugand (Figura 3, No. 18)

Granos radiosimétricos, isopolares, tricolporados, esferoidales a subprolados, ámbito circular; DE: 20-22, DP: 21-25 $\mu \mathrm{m}$. Exina: $2-3 \mu \mathrm{m}$, microreticulada, homobrocada, simplicolumelada. Poro elípticos lalongados $(6-10 \times 3-6 \mu \mathrm{m})$. Colpos tan largos como los granos, de $2-4 \mu \mathrm{m}$ de ancho. M.E.: LABUN 501.

Trifolium repens L. (Figura 10S, https://www.raccefyn.co/ index.php/raccefyn/article/view/61/677; No. 46)
Granos radiosimétricos, isopolares, tricolporados, proladoesferoidales a prolados, ámbito circular o trilobado; DE: 2231, DP: $30-35 \mu \mathrm{m}$. Exina: $2-3 \mu \mathrm{m}$, fosulada. Poros lalongados cóncavos $(6-10 \times 3-5 \mu \mathrm{m})$. Colpos tan largos como los granos, de 2-3 $\mu \mathrm{m}$ de ancho. M.E.: LABUN 1180.

\section{FABACEAE (Mimosoideae)}

\section{Inga oerstediana Benth. Ex Seem. (Figura 4, No. 19)}

Poliadas elípticas de 32 a 44 granos, 170-200 x 130-150 $\mu \mathrm{m}$ de diámetro. Granos asimétricos, apolares, periporados (410 poros), de $35-50 \mu \mathrm{m}$. Exina: 3-7 $\mu \mathrm{m}$, areolada. Poros circulares $(6-9 \mu \mathrm{m})$ cubiertos por membrana ectexínica. M.E.: LABUN 783.

Mimosa albida Humb. \& Bonpl. ex Willd. (Figura 3, No. 20)

Tétradas esféricas de 9-11 $\mu \mathrm{m}$ de diámetro. Granos asimétricos, apolares, inaberturados. Exina: $<0,5 \mu \mathrm{m}$, microreticulada. M.E.: LABUN 647.

Mimosa pigra L. (Figura 10S, No. 47)

Tétradas elípticas de 14-18 x 22-25 $\mu \mathrm{m}$ de diámetro. Granos asimétricos, apolares, inaberturados, de $10-14 \mu \mathrm{m}$. Exina: $<1-1 \mu \mathrm{m}$, microreticulada. M.E.: ICN 5537.

Mimosa pudica L. (Figura 3, No. 21)

Tétradas esféricas de $11-12 \mu \mathrm{m}$ de diámetro. Granos asimétricos, apolares, inaberturados. Exina: $<0,5 \mu \mathrm{m}$, escabrada. M.E.: LABUN 334.

\section{HYPERICACEAE}

Vismia baccifera (L.) Triana \& Planch. (Figura 10S, No. 48)

Granos radiosimétricos, isopolares, tricolporados, esferoidales a subprolados, ámbito circular; DE: 23-28, DP: $25-34 \mu \mathrm{m}$. Exina: $2-3 \mu \mathrm{m}$, reticulada. Retículo heterobrocado, más pequeño hacia los polos y colpos, simplicolumelado a pluricolumelado, muro de $\leq 1-2 \mu \mathrm{m}$ de ancho, lumen de $1-3 \mu \mathrm{m}$. Poros lalongados a circulares anulados $(4-7 \times 3-4 \mu \mathrm{m})$. Colpos con margo, tan largos como los granos, de $2-4 \mu \mathrm{m}$ de ancho. Lado apocolpio de 6-11 $\mu$ m. M.E.: LABUN 809.

\section{ICACINACEAE}

Calatola costaricensis Standl. (Figura 10S, No. 49)

Granos radiosimétricos, isopolares, tricolporados, suboblados a esferoidales, ámbito circular, 13-17 $\mu \mathrm{m}$ de diámetro. Exina: 1,5-2 $\mu \mathrm{m}$, microreticulada. Poros lalongados, con fastigio, (3 x $1 \mu \mathrm{m}$ ). Colpos cortos y angostos, de $4-8 \mu \mathrm{m}$ de largo, $<1$ $1 \mu \mathrm{m}$ de ancho. M.E.: ICN 4219.

\section{LAMIACEAE}

Hyptis mutabilis (Rich.) Briq. (Figura 10S, No 50)

Granos radiosimétricos, isopolares, estefanocolpados (seis 
colpos), oblados a oblado-esferoidales, ámbito elíptico; DE: 33-42, DP: $26-37 \mu \mathrm{m}$. Exina: $2-3 \mu \mathrm{m}$, reticulada. Retículo heterobrocado, más pequeño en los polos, simplicolumelado, muro de $<1 \mu \mathrm{m}$ de ancho, lumen de 1-6 $\mu \mathrm{m}$. Colpos con restos de membrana ectexínica, tan largos como los granos, de $5-8 \mu \mathrm{m}$ de ancho. Lumen con elementos ectexínicos. M.E.: LABUN 645.

\section{Salvia occidentalis Sw. (Figura 10S, No. 51)}

Granos radiosimétricos, isopolares, estefanocolpados (seis colpos), oblados a oblado-esferoidales, ámbito elíptico; DE: 39-49, DP: $25-40 \mu \mathrm{m}$. Exina: $2-3 \mu \mathrm{m}$, reticulada. Retículo homobrocado, simplicolumelado, muro de $<1 \mu \mathrm{m}$ de ancho, lumen de $\leq 1-2 \mu \mathrm{m}$. Colpos tan largos como los granos, de $1-5 \mu \mathrm{m}$ de ancho. M.E.: LABUN 484.

\section{LAURACEAE}

Persea americana Mill. (Figura 10S, No. 52)

Granos asimétricos, apolares, inaberturados, esferoidales, ámbito circular, de $37-50 \mu \mathrm{m}$ de diámetro. Exina: $1 \mu \mathrm{m}$, microequinada. M.E.: LABUN 713.

\section{LYTHRACEAE}

\section{Adenaria floribunda Kunth (Figura 10S, No. 53)}

Granos con simetría radial, isopolares, tricolporados, prolados a esferoidales, ámbito circular o trilobado; DE: 14-24, DP: 13$27 \mu \mathrm{m}$. Exina: $1,5-3 \mu \mathrm{m}$, fosulada-perforada; poros circulares anulados, a veces con constricción en el medio $(3-6 \mu \mathrm{m})$; colpos tan largos como los granos, de 2-4 $\mu \mathrm{m}$ de ancho; lado apocolpio de 4-8 $\mu$ m. M.E.: LABUN 1277.

\section{MALPIGHIACEAE}

Stigmaphyllon columbicum Nied. (Figura 11S, https:// www.raccefyn.co/index.php/raccefyn/article/view/61/678; No. 54)

Granos asimétricos, apolares, colpados extraporados, esferoidales, ámbito circular, 38-56 $\mu \mathrm{m}$ de diámetro. Exina: 4-6 $\mu \mathrm{m}$, rugulada en areas distantes y microfosulada en áreas cercanas a colpos y poros. Poros circulares de $8-12 \mu \mathrm{m}$, generalmente, 6 , aunque pueden variar entre 5 y 8 . Colpos bifurcados y de tamaño variable. M.E.: LABUN 741.

\section{MALVACEAE (Bombacoideae)}

\section{Ceiba pentandra (L.) Gaertn. (Figura 11S, No. 55)}

Granos radiosimétricos, isopolares, brevitricolporados, oblados esferoidales, ámbito triangular convexo; DE: 52-60, DP: $42-50 \mu \mathrm{m}$. Exina: $2-4 \mu \mathrm{m}$, reticulada. Retículo homobrocado, simplicolumelado, columelas de tamaño variable y dispersas en el lumen, muro de $1 \mu \mathrm{m}$ de ancho, lúmen de $3-10 \mu \mathrm{m}$. Poros circulares y anulados $(7-8 \times 2-3 \mu \mathrm{m})$. Colpos costados $(15-20 \mathrm{x}$ 2-3 $\mu \mathrm{m})$. M.E.: ICN 5366.
Ochroma pyramidale (Cav. ex Lam.) Urb. (Figura 11S, No. 56)

Granos radiosimétricos, isopolares, brevitricolporados, obladoesferoidales a prolado- esferoidales, ámbito triangular convexo; DE: $77-95$, DP: $70-80 \mu \mathrm{m}$. Exina: 4-5 $\mu \mathrm{m}$, reticulada. Retículo heterobrocado, simplicolumelado a duplicolumelado, muro de $2 \mu \mathrm{m}$ de ancho, lumen de 6-18 $\mu \mathrm{m}$. Poros elípticos lolongados

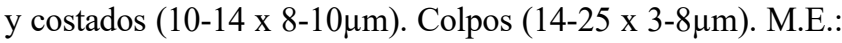
LABUN 1312.

Pseudobombax septenatum (Jacq.) Dugand (Figura 11S, No. 57)

Granos radiosimétricos, isopolares, brevitricolpados, peroblados a oblados, ámbito triangular recto o cóncavo; DE: 52-62, DP: $27-35 \mu \mathrm{m}$. Exina: $2-3 \mu \mathrm{m}$, más ancha en los polos, reticulada. Retículo heterobrocado, más pequeño en los intercolpios, simplicolumelado, muro de $1 \mu \mathrm{m}$ de ancho, lumen de $1-7 \mu \mathrm{m}$. Colpos costados $(15-20$ x 2-4 $\mu \mathrm{m})$. M.E.: ICN 5131.

\section{MALVACEAE (Byttnerioideae)}

Melochia parvifolia Kunth (Figura 12S, https://www.raccefyn. co/index.php/raccefyn/article/view/61/679; No.58)

Granos dimórficos, radiosimétricos, isopolares, obladoesferoidales a prolado-esferoidales, ámbito circular. Exina: $2-3 \mu \mathrm{m}$; poros lalongados, sobresalientes y con costa prominente. Morfotipo 1: tricolporado $(35-50 \mu \mathrm{m})$; exina reticulada. Retículo heterobrocado, más pequeño hacia los colpos, simplicolumelado, muro de $<1 \mu \mathrm{m}$, lumen de $<1-3 \mu \mathrm{m}$, columelas visibles en el lumen. Poros (6-10 x 4-8 $\mu \mathrm{m})$. Colpos (30-40, 1-3 $\mu \mathrm{m})$. Morfotipo 2: tricolporado, tetracolporado, 50$60 \mu \mathrm{m}$, exina microequinada, poros $(10-12 \times 6-8 \mu \mathrm{m})$. Colpos 25-30 x 1-3 $\mu$ m. M.E.: LABUN 515.

\section{MALVACEAE (Grewioideae)}

\section{Corchorus orinocensis Kunth (Figura 12S, No. 59)}

Granos radiosimétricos, isopolares, tricolporados, prolados, ámbito circular o trilobado; DE: 28-38, DP: 46-55 $\mu \mathrm{m}$. Exina: 2,5-3 $\mu \mathrm{m}$, reticulada y con columelas visibles en el lumen; retículo heterobrocado, elongado, simplicolumelado, más pequeño hacia los colpos, muro de $<1 \mu \mathrm{m}$, lúmen de $1-4 \mu \mathrm{m}$. Poros lalongados (10-20 x 5-13 $\mu \mathrm{m})$. Colpos tan largos como los granos, de 1-6 $4 \mathrm{~m}$ de ancho, con costa. M.E.: LABUN 431.

\section{Heliocarpus americanus L. (Figura 3, No. 22)}

Granos radiosimétricos, isopolares, tricolporados, prolados,

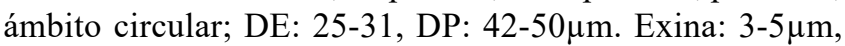
reticulada. Retículo heterobrocado, elongado, simplicolumelado, más pequeño hacia los colpos, muro de $<1 \mu \mathrm{m}$, lumen de $<1-3 \mu \mathrm{m}$. Poros lalongados (11-15 x 2-6 $\mu \mathrm{m})$; nexina engrosada en los poros; colpos con margo, tan largos como los granos, de 2-7 $\mu \mathrm{m}$ de ancho. M.E.: LABUN 460. 


\section{MALVACEAE (Malvoideae)}

Abutilon $\boldsymbol{x}$ hybridum Voss (Figura 12S, No. 60)

Granos radiosimétricos, isopolares, brevitricolporados, suboblados a esferoidales, ámbito circular; DE: 56-78, DP: 50$73 \mu \mathrm{m}$. Exina: $8-12 \mu \mathrm{m}$, equinada y granulada. Espinas de 4-5 $\mu \mathrm{m}$ de ancho x 5-6 $\mu \mathrm{m}$ de largo, con columelas prominentes en la base y punta redondeada. Poro circular de 7-12 $\mu \mathrm{m}$, con ánulo de $4 \mu \mathrm{m}$ de ancho. Colpos (10-15 x 1-2 $\mu \mathrm{m})$. M.E.: LABUN 1167.

Sida acuta Burm.f. (Figura 13S, https://www.raccefyn.co/ index.php/raccefyn/article/view/61/680; No. 61)

Granos asimétricos, apolares, periporados ( $<10$ poros), esferoidales, ámbito circular, 71-92 $\mu$. Exina: $8-12 \mu \mathrm{m}$, equinada. Espinas de 4-5 $\mu \mathrm{m}$, puntiagudas con base columelada. Poros circulares anulados, de 5-7 $\mu$ m. M.E.: LABUN 341.

\section{MELASTOMATACEAE}

Conostegia icosandra (Sw. ex Wikstr.) Urb. (Figura 12S, No. 62)

Granos radiosimétricos, isopolares, heterocolpados, oblados esferoidales a prolados esferoidales, ámbito hexalobado; DE: $16-18$, DP: $15-18 \mu \mathrm{m}$. Exina: $<1-1 \mu \mathrm{m}$, escabrada. Poro lalongados, conspicuos $(5-7 \times 2-4 \mu \mathrm{m})$. Colpos tan largos como los granos, de 1-5 $\mu \mathrm{m}$ de ancho. M.E.: ICN 0062.

Miconia dodecandra Cogn. (Figura 13S, No. 63)

Granos radiosimétricos, isopolares, heterocolpados, obladoesferoidales a prolados, ámbito hexalobado; DE: 19-29, DP: $25-35 \mu \mathrm{m}$. Exina: $1-2 \mu \mathrm{m}$ escabrada y fosulada. Poros lalongados $(6-10 \times 2-4 \mu \mathrm{m})$. Colpos tan largos como los

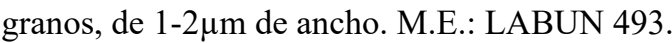

\section{Miconia minutiflora (Bonpl.) DC. (Figura 13S, No. 64)}

Granos radiosimétricos, isopolares, heterocolpados, proladoesferoidales a prolados, ámbito hexalobado; DE: 12-20, DP: 19-25 . Exina: $1-2 \mu \mathrm{m}$, psilada o con ornamentación poco visible. Poros lalongados, incospicuos $(<1-2 \mu \mathrm{m})$. Colpos más cortos que lós colporos, de $<1-1 \mu \mathrm{m}$ de ancho. M.E.: LABUN 646.

\section{Miconia serrulata (DC.) Naudin (Figura 13S, No. 65)}

Granos radiosimétricos, isopolares, heterocolpados rara vez sincolpados, esferoidales a prolados, ámbito hexalobado; DE: $16-23$, DP: $20-27 \mu \mathrm{m}$. Exina: $1-2 \mu \mathrm{m}$, escabrada o microrreticulada. Poro lalongados a veces incospicuos (2-7 x $1-5 \mu \mathrm{m})$. Colpos más cortos que los colporos, de $<1-1 \mu \mathrm{m}$ de ancho. M.E.: LABUN 781.

\section{Tibouchina longifolia (Vahl) Baill. (Figura 13S, No. 66)}

Granos radiosimétricos, isopolares, heterocolpados, esferoidales a prolados, ámbito hexalobado; DE: 14-21, DP: $17-$
$22 \mu \mathrm{m}$. Exina: 1-2 $\mu \mathrm{m}$, escabrada. Poros lalongados $(2-4 \mathrm{x}$ $<1-3 \mu \mathrm{m})$. Colpos más cortos que los colporos, de $<1-2 \mu \mathrm{m}$ de ancho. M.E.: LABUN 667.

\section{MORACEAE}

Poulsenia armata (Miq.) Standl. (Figura 3, No. 23)

Granos radiosimétricos, isopolares, triporados, suboblados a oblado-esferoidales, ámbito circular, DE: 18-22, DP: $15-$ $17 \mu \mathrm{m}$. Exina: $1 \mu \mathrm{m}$, escabrada. Poros circulares y vestibulados

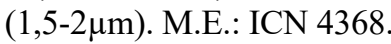

\section{Pseudolmedia laevigata Trécul (Figura 13S, No. 67)}

Granos radiosimétricos, isopolares, triporados o tetraporados, suboblados a prolado- esferoidales, ámbito circular, DE: 1719, DP: $14-17 \mu \mathrm{m}$. Exina: $<1 \mu \mathrm{m}$, ligeramente escabrada.

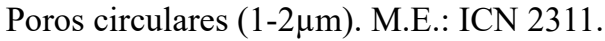

Trophis racemosa (L.) Urb. (Figura 13S, No. 68)

Granos radiosimétricos, isopolares, diporados pocas veces triporados, suboblados a prolado-esferoidales, ámbito circular; DE: 19-23, DP: 17-21 $\mu \mathrm{m}$. Exina: $<1 \mu \mathrm{m}$, ligeramente

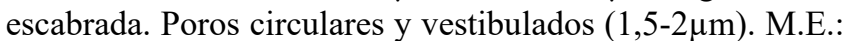
ICN 977.

\section{MUNTINGIACEAE}

Muntingia calabura L. (Figura 4, No. 24)

Granos radiosimétricos, isopolares, tricolporados, obladoesferoidales a prolado-esferoidales, ámbito circular o trilobado;

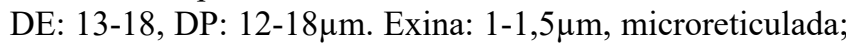
retículo heterobrocado simplicolumelado, más pequeño hacia los colpos y poros. Poros lalongados a circulares (4-5 x $1-5 \mu \mathrm{m})$; colpos tan largos como los granos, de $1-5 \mu \mathrm{m}$ de ancho, a veces con constricción ecuatorial; lado apocolpio de 3-5 $\mu$ m. M.E.: LABUN 444.

\section{MYRTACEAE}

Calycolpus moritzianus (O.Berg) Burret (Figura 13S, No. 69)

Granos radiosimétricos, isopolares, tricolporados, peroblados a suboblados, ámbito triangular convexo; DE: 19-27, DP:

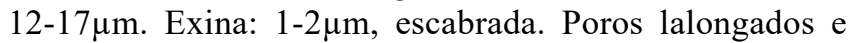
inconspicuos $(3-5 \times<1-1 \mu \mathrm{m})$. Colpos de $1-3 \mu \mathrm{m}$ de ancho. M.E.: LABUN 477.

Eucalyptus globulus Labill. (Figura 14S, https://www. raccefyn.co/index.php/raccefyn/article/view/61/681; No. 70)

Granos radiosimétricos, isopolares, tricolporados parasincolpados, peroblados a oblados, ámbito triangular cóncavo; DE: 31-41, DP: $12-22 \mu \mathrm{m}$. Exina: $2-3 \mu \mathrm{m}$, psilada. Poros

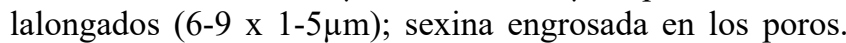
Colpos de $1-2 \mu \mathrm{m}$ de ancho. Lado apocolpio de $8-10 \mu \mathrm{m}$. M.E.: LABUN 579.

Myrcia splendens (Sw.) DC. (Figura 14S, No. 71) 
Granos radiosimétricos, isopolares, tricolporados, oblados, ámbito triangular convexo; DE: 17-20, DP: 9-14 $\mu$ m. Exina: $<1-1 \mu \mathrm{m}$, escabrada. Poro lalongados con fastigio (4-7 $\mathrm{x}<1-$ $1 \mu \mathrm{m})$. Colpos de $1 \mu \mathrm{m}$ de ancho. M.E.: LABUN 331.

\section{Psidium guajava L. (Figura 14S, No. 72)}

Granos radiosimétricos, isopolares, tricolporados, oblados a suboblados, ámbito triangular convexo, DE: 19-22, DP: 11-15 $\mu \mathrm{m}$. Exina: $1-2 \mu \mathrm{m}$, escabrada o rugulada. Poros lalongados con fastigio (5-7 x 1-2 $\mu \mathrm{m})$. Colpos de $1-2 \mu \mathrm{m}$ de ancho. M.E.: LABUN 19.

\section{Syzygium jambos (L.) Alston (Figura 14S, No. 73)}

Granos radiosimétricos, isopolares, tricolporados parasincolpados, peroblados a oblados, ámbito triangular convexo; DE: 25-36, DP: $10-19 \mu \mathrm{m}$. Exina: $2 \mu \mathrm{m}$, psilada. Poros lalongados con fastigio $(8-10 \times 1-4 \mu \mathrm{m})$; sexina engrosada en los poros. Colpos de $1-5 \mu \mathrm{m}$ de ancho. Lado apocolpio de 4-5 $\mu$ m. M.E.: LABUN 1767.

\section{OLEACEAE}

Fraxinus chinensis Roxb. (Figura 4, No. 25)

Granos radiosimétricos, isopolares, estefanocolpados (cuatro a cinco colpos), oblados a oblado-esferoidales, ámbito circular, tetralobado o pentalobado; DE: 33-40, DP: 26$30 \mu \mathrm{m}$. Exina: $2-3 \mu \mathrm{m}$, reticulada. Retículo homobrocado, simpli-columelado, muro de $<1 \mu \mathrm{m}$ de ancho, lumen de $<1$ -

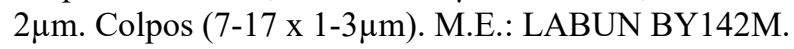

\section{PHYLLANTHACEAE}

Hieronyma fendleri Briq. (Figura 4, No. 26)

Granos radiosimétricos, isopolares, tricolporados, prolados a perprolados, ámbito circular o trilobado; DE: 12-18, DP: 20-35 $\mu \mathrm{m}$. Exina: $1-2 \mu \mathrm{m}$, microreticulada columelada. Poros

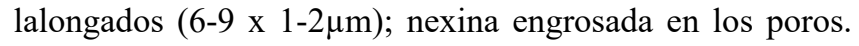
Colpos tan largos como los granos, de $1-3 \mu \mathrm{m}$ de ancho. M.E.: LABUN 1789.

\section{PHYTOLACCACEAE}

Phytolacca rivinoides Kunth \& C.D.Bouché (Figura 14S, No. 74)

Granos radiosimétricos, isopolares, tricolporados, suboblados a prolado-esferoidales, ámbito circular, DE: 26-35, DP: 27$33 \mu \mathrm{m}$. Exina: $1-3 \mu \mathrm{m}$, granulada. Poro lolongados, aveces inconspicuos $(7-11 \times 3-5 \mu \mathrm{m})$. Colpos tan largos como los granos, de 3-5 $\mu \mathrm{m}$ de ancho, con borde irregular y restos de membrana ectexínica. Lado apocolpio de $8-14 \mu \mathrm{m}$. M.E.: LABUN 2087.

\section{PIPERACEAE}

Piper aduncum L. (Z 4, No. 27)

Granos con simetría bilateral, isopolares, monocolpados, oblados a esferoidales; DE: 7-10, DP: 8-12 $\mu \mathrm{m}$. Exina: $<1 \mu \mathrm{m}$, aparentemente microrreticulada. M.E.: LABUN 375.

\section{POLYGONACEAE}

Triplaris americana L. (Figura 14S, No. 75)

Granos radiosimétricos, isopolares, tricolporados, esferoidales a subprolados, ámbito circular; DE: 30-39, DP: 36$45 \mu \mathrm{m}$. Exina: $3-5 \mu \mathrm{m}$, rugulada o verrugada; verrugas de tamaño variable, de $1-5 \mu \mathrm{m}$ de ancho. Poros lalongados (4-6 x 1-5 $\mu \mathrm{m})$. Colpos tan largos como los granos, de $1-4 \mu \mathrm{m}$. Lado apocolpio de 5-9 $\mu$ m. M.E.: LABUN 507.

\section{PRIMULACEAE}

Ardisia guianensis (Aubl.) Mez (Figura 5, No. 28)

Granos radiosimétricos, isopolares, tricolporados, proladoesferoidales a subprolados, ámbito circular o trilobado; DE: 10-13, DP: $12-15 \mu \mathrm{m}$. Exina: $1-2 \mu \mathrm{m}$, microrreticulada. Poros lalongados $(3 \times 1 \mu \mathrm{m})$; nexina ensanchada en los bordes de los poros. Colpos tan largos como los granos, de $1 \mu \mathrm{m}$ de ancho. M.E.: ICN 4609.

Cybianthus nevadensis (Mez) G.Agostini (Figura 5, No. 29)

Granos radiosimétricos, isopolares, tricolporados, obladoesferoidales a subprolados, ámbito trilobado, DE: 18-22, DP: 20-23 $\mu \mathrm{m}$. Exina: $1-2 \mu \mathrm{m}$, psilada o ligeramente escabrada. Poros lalongados, aveces con constricción ecuatorial (6-10

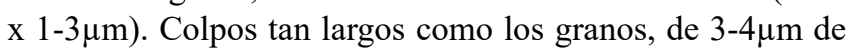
ancho. Lado apocolpio de 4-7 $\mu$ m. M.E.: LABUN 2101.

\section{PROTEACEAE}

\section{Roupala montana Aubl. (Figura 14S, No. 76)}

Granos radiosimétricos, isopolares, triporados, oblados a suboblados, ámbito triangular recto; DE: $30-35$, DP: 18$24 \mu \mathrm{m}$. Exina: $1,5-2 \mu \mathrm{m}$, escabrada fosulada. Poros circulares (3-6 $\mu \mathrm{m})$. M.E.: ICN L61.

\section{RHAMNACEAE}

Gouania polygama (Jacq.) Urb. (Figura 5, No. 30)

Granos radiosimétricos, isopolares, tricolporados, suboblados a oblado-esferoidales, ámbito angular; DE: 25-35, DP: $25-31 \mu \mathrm{m}$. Exina: $2 \mu \mathrm{m}$, escabrada; poros lalongados (8-10 x $2-5 \mu \mathrm{m})$. Colpos tan largos como los granos, de $4-5 \mu \mathrm{m}$ de ancho; margo con escabras más grandes; lado apocolpio de

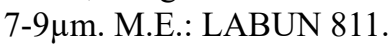

\section{ROSACEAE}

Rubus urticifolius Poir. (Figura 5, No. 31)

Granos radiosimétricos, isopolares, tricolporados, obladoesferoidales a prolados, ámbito circular o trilobado; DE: 22$30 \mu \mathrm{m}$, DP: $23-30 \mu \mathrm{m}$. Exina: $2 \mu \mathrm{m}$, estriada microrreticulada; poros lalongados o irregulares $(8 \times 1-7 \mu \mathrm{m})$. Colpos con 
márgenes irregulares, tan largos como los granos, de 1-5 $\mu \mathrm{m}$ de ancho. Lado apocolpiode 6-11 $\mu$ m. M.E.: LABUN 459.

\section{RUBIACEAE}

Coffea arabica L. (Figura 5, No. 32)

Granos polimórficos radiosimétricos, isopolares o heteropolares, tricolporados, estefanocolporados (cuatro colpos) o pericolporados, a veces sincolpados, oblado-esferoidales a prolado-esferoidales, ámbito circular o cuadrangular; DE: $32-40 \mu \mathrm{m}$, DP: $30-38 \mu \mathrm{m}$. Exina: $2 \mu \mathrm{m}$, granulada, perforada, foveolada, fosulada, areolada o reticulada (en la Figura 5 No. 32 aparece ornamentación reticulada, fosulada); poros lalongados, irregulares o circulares, a veces anulados (2-8 x 3-11 $\mu \mathrm{m})$. Colpos con márgenes irregulares y de longitud variable, de 3-7 $\mu \mathrm{m}$ de ancho; a veces se presentan colpos latitudinales en el área polar o ecuatorial. M.E.: LABUN M1C01.

\section{Spermacoce verticillata L. (Figura 14S, No. 77)}

Granos radiosimétricos, isopolares, estefanocolpados (seis a siete colpos), suboblados a oblado-esferoidales, ámbito circular; DE: $32-41$, DP: $30-37 \mu \mathrm{m}$. Exina: $2-4 \mu \mathrm{m}$, colume-

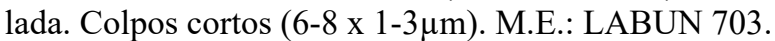

Warszewiczia coccinea (Vahl) Klotzsch (Figura 15S, https://www.raccefyn.co/index.php/raccefyn/article/ view/61/682; No. 78)

Granos radiosimétricos, isopolares, tricolporados, suboblados a subprolados, ámbito circular o trilobado; DE: 19-28, DP: 19-29 $\mu \mathrm{m}$. Exina: $2-4 \mu \mathrm{m}$, reticulada. Retículo homobrocado, simplicolumelado, muro de $1 \mu \mathrm{m}$ de ancho, lumen de $2-4 \mu \mathrm{m}$. Poros circulares anulados $(3-5 \mu \mathrm{m})$. Colpo ecuatorial de 5-6 $\mu \mathrm{m}$ de ancho. Colpos tan largos como los granos, de $3-5 \mu \mathrm{m}$ de ancho. Lado apocolpio de 5-9 $\mu$ m. M.E.: LABUN 672.

\section{RUTACEAE}

Citrus aurantium L. (Figura 15S, No. 79)

Granos radiosimétricos, isopolares, estefanocolporados (cuatro colpos), oblados a prolado-esferoidales, ámbito circular o tetralobado; DE: 26-37, DP: $26-40 \mu \mathrm{m}$. Exina: $2-4 \mu \mathrm{m}$, reticulada en el mesocolpio y columelada en el apocolpio. Retículo heterobrocado, más pequeño en los polos, simplicolumelado o duplicolumelado, muro de $1-2 \mu \mathrm{m}$ de ancho, lumen de $1-2 \mu \mathrm{m}$. Poros lalongados (6-12 x 2-6 $\mu \mathrm{m})$. Colpos tan largos como los granos, de $1-4 \mu \mathrm{m}$ de ancho. Lado apocolpio de 7-12 $\mu \mathrm{m}$. M.E.: LABUN 287.

\section{SALICACEAE}

Casearia corymbosa Kunth (Figura 15S, No. 80)

Granos radiosimétricos, isopolares, tricolporados, esferoidales a subprolados, ámbito circular; DE: 20-27, DP: $22-$ $29 \mu \mathrm{m}$. Exina: $1 \mu \mathrm{m}$, perforada. Poro lalongados $(7-10 \mathrm{x}$

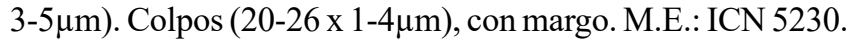

\section{SAPINDACEAE}

Cupania americana L. (Figura 15S, No. 81)

Granos radiosimétricos, isopolares, tricolporados parasincolpados, peroblados a oblados, ámbito triangular recto o concavo; DE: $36-41$, DP: 18-22 $\mu \mathrm{m}$. Exina: $1-4 \mu \mathrm{m}$, escabrada

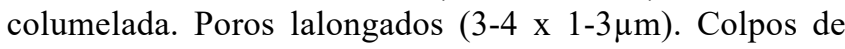

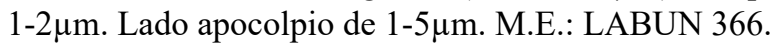

Melicoccus bijugatus Jacq. (Figura 5, No. 33)

Granos radiosimétricos, isopolares, tricolporados, obladoesferoidales a prolados, ámbito circular o trilobado; DE: 1723, DP: $20-27 \mu \mathrm{m}$. Exina: $1-2 \mu \mathrm{m}$, psilada. Poros lalongados (3-5 x 1-2 $\mu \mathrm{m})$, costados. Colpos tan largos como los granos, de $1-2 \mu \mathrm{m}$ de ancho. Lado apocolpio de 5-9 $\mu \mathrm{m}$. M.E.: LABUN 408.

\section{Melicoccus oliviformis Kunth (Figura 5, 34)}

Granos radiosimétricos, isopolares, tricolporados, oblados a oblado-esferoidales, ámbito triangular convexo, DE: 2631, DP: 20-26 $\mu \mathrm{m}$. Exina: 1-2 $\mu \mathrm{m}$, escabrada y estriada. Poros compuestos, mesoapertura circular lolongada $(5-8 \times 4-6 \mu \mathrm{m})$, exoapertura lalongada $(6-9 \times 1 \mu \mathrm{m})$. Colpos tan largos como

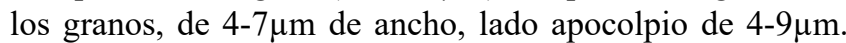
M.E.: LABUN 2086.

\section{Paullinia macrophylla Kunth (Figura 15S, No. 82)}

Granos radiosimétricos, isopolares, triporados, oblados, ámbito triangular recto o convexo, DE: 38-50, DP: $23-$ $32 \mu \mathrm{m}$. Exina: $2-3 \mu \mathrm{m}$, columelada y perforada. Poros cir-

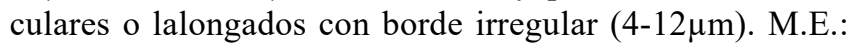
LABUN 2097.

\section{Serjania paniculata Kunth (Figura 15S, No. 83)}

Granos radiosimétricos, heteropolares, tricolporados sincolpados, peroblados a oblados, ámbito triangular, DE: 37-48, DP: $20-26 \mu \mathrm{m}$. Exina: $1,5 \mu \mathrm{m}$, columelada y perforada. Poros vestibulados de forma irregular $(1-4 \mu \mathrm{m})$. Colpos angostos, visibles solo por un hemisferio, de $<1 \mu \mathrm{m}$ de ancho. M.E.: LABUN 2095.

\section{SOLANACEAE}

Brugmansia pittieri (Saff.) Moldenke (Figura 16S, https://www.raccefyn.co/index.php/raccefyn/article/ view/61/683; No. 84)

Granos radiosimétricos, isopolares, tricolporados zonorados, suboblados a prolado-esferoidales, ámbito circular; DE: 56-

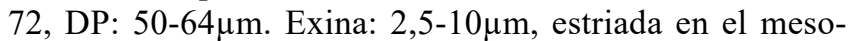
colpio, rugulada en el apocolpio, muro de 1-2 $\mu \mathrm{m}$ de ancho, lumen de $<1-1 \mu \mathrm{m}$. Poros circulares $(4-10 \mu \mathrm{m})$, anulados. Colpos inconspicuos, cortos y costados. Colpo ecuatorial de 
6-10 $\mu \mathrm{m}$ de ancho. M.E.: ICN 5099.

Solanum aturense Dunal (Figura 16S, No. 85)

Granos radiosimétricos, isopolares, tricolporados zonorados,

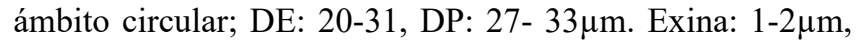
escabrada. Poros lalongados y sobresalientes (11-21 x 4-81$2 \mu \mathrm{m})$. Colpos tan largos como los granos, de $4-8 \mu \mathrm{m}$ de ancho. Colpo ecuatorial presente. M.E.: LABUN 614.

\section{URTICACEAE}

\section{Cecropia peltata L. (Figura 5, No. 35)}

Granos con simetría bilateral, isopolares, diporados pocas veces triporados, subprolados a prolados, ámbito circular o triangular en los triporados; DE: $8-12 \mu \mathrm{m}$, DP: $12-17 \mu \mathrm{m}$. Exina: $<1 \mu \mathrm{m}$, escabrada. Poros circulares de $1 \mu \mathrm{m}$ de diámetro. M.E.: LABUN 727.

\section{VITACEAE}

Cissus verticillata (L.) Nicolson \& C.E.Jarvis (Figura 16S, No. 86)

Granos radiosimétricos, isopolares, tricolporados, subprolados a prolados, apiculados, ámbito trilobado; DE: 30-45, DP: $52-62 \mu \mathrm{m}$. Exina: $2-3 \mu \mathrm{m}$, granulada perforada. Poros lalongados $(8-14 \times 2-7 \mu \mathrm{m})$. Colpos tan largos como los granos, de 1-4 $\mu \mathrm{m}$ de ancho. Lado apocolpio de $3-5 \mu \mathrm{m}$. M.E.: LABUN 726.

Vitis tiliifolia Humb. \& Bonpl. ex Schult. (Figura 5, No. 36)

Granos radiosimétricos, isopolares, tricolporados, subprolados a prolado-esferoidales, ámbito hexagonal; DE: 20$30 \mu \mathrm{m}$, DP: $21-36 \mu \mathrm{m}$. Exina: $1,5-2 \mu \mathrm{m}$, microrreticulada en el apocolpio y escabrada en el mesocolpio. Poros circulares con borde engrosado $(2-4 \mu \mathrm{m})$. Colpos tan largos como los granos, de $1-2 \mu \mathrm{m}$ de ancho. Lado apocolpio de 5-8 $\mu \mathrm{m}$; margo psilado. M.E.: LABUN 1814.

\section{Conclusiones}

Presentamos las descripciones polínicas de 122 especies, con la certeza de que 59 aparecen en la miel de $A$. mellifera producida en la Sierra Nevada de Santa Marta. Entre las restantes se encuentran las especies afines a los morfotipos que únicamente se identificaron a nivel de género o familia (Nates Parra, et al., 2013, León-Bonilla, en preparación), pues su morfología polínica no permite identificarlas con un mayor grado de resolución mediante microscopía óptica únicamente. Algunos ejemplos de las familias con granos de polen menos diferenciables son Poaceae, Asteraceae, Melastomataceae, Moraceae y Myrtaceae, entre otras (Roubik \& Moreno, 1991; Palacios-Chávez, et al., 1991). En la tabla 1 aparecen las especies que corresponden a los morfotipos no identificados a nivel de especie, así como información sobre los nombres comúnes, la oferta de néctar y los rangos de abundancia en la miel, además de algunas observaciones ecológicas relativas al hábito, el origen geográfico y la distribución altitudinal.

Las especies descritas se distribuyen en 54 familias, entre las cuales las más abundantes en especies son Asteraceae, con 14, Fabaceae, con 9, Malvaceae, con 8, Euphorbiaceae, con 6, y Melastomataceae, Myrtaceae, Poaceae y Sapindaceae, con 5 cada una. Las principales especies nectaríferas que aparecen como polen dominante en la miel son $A$, inulifolium, C.morifolia, B. simaruba, C. hirtus (Croton spp.), G. sepium, I. oerstediana, A. floribunda, H. americanus, M. calabura, R. urticifolius (Rubus spp.), C. arabica y V. tiliifolia. Las especies no productoras de néctar que también aparecen como polen dominante son A. graveolens, C. palmata, B. guaduensis (Begonia spp.), T. micrantha, $H$. racemosum, D. dentatus, M. albida, M. pudica, P. armata (Moraceae spp.), P. aduncum (Piper spp.) y C. peltata. El $50 \%$ de las especies son árboles, $21 \%$ corresponde a arbustos, $21 \%$ a hierbas y $7 \%$ a bejucos; $59 \%$ son frecuentes en áreas intervenidas y $13 \%$ son exóticas.

La mayoría de las especies aquí descritas son plantas comunes también visitadas por A. mellifera en otras zonas cafeteras de Colombia (Castaño \& Fonnegra, 1981, Echeverry, 1984, Girón-Vanderhuck, 1995, Sánchez, 1995, Giraldo, et al., 2011, Velandia, et al., 2012, Nates-Parra, et al., 2013), de tal manera que este catálogo no solo servirá como herramienta para los análisis melisopalinológicos de la Sierra Nevada de Santa Marta sino también para otras regiones similares del país.

\section{Agradecimientos}

A Colciencias, al Instituto de Ciencia y Tecnología de Alimentos, ICTA, y al Departamento de Biología de la Universidad Nacional de Colombia, por el apoyo logístico y financiero al proyecto "Identificación de marcadores para la miel de abejas originaria de cultivos de café orgánico en la Sierra Nevada de Santa Marta", (código QUIPU 201010017326). A los profesores Luis Carlos Jiménez y Carlos Parra, por permitir el ingreso al Herbario Nacional

\section{Información suplementaria}

Figura 1S. ARECACEAE: 1. Bactris gasipaes var. Chichagu. 2. Euterpe precatoria. 3. Geonoma interrupta. CYPERACEAE:
4. Rhynchospora barbata. 5. Scleria mitis. POACEAE: 6 . Brachiaria brizantha. 7. Holcus lanatus. 
Figura 2S. POACEAE: 8. Melinis minutiflora. 9. Pennisetum purpureum. 10. Zea mays. ACTINIDACEAE: 11. Saurauia yasicae. AMARANTHACEAE: 12. Iresine diffusa.

Figura 3S. ANACARDIACEAE: 13. Mangifera indica. AQUIFOLIACEAE: 14. Ilex kunthiana. ARALIACEAE: 15. Oreopanax capitatus. ASTERACEAE: 16. Acmella ciliata. 17. Baccharis trinervis. 18. Bidens pilosa. 19. Clibadium surinamense.

Figura 4S. ASTERACEAE: 20. Emilia sonchifolia. 21. Hypochaeris radicata. 22. Lepidaploa canescens. 23. Mikania micrantha. 24. Neurolaena lobata.

Figura 5S. ASTERACEAE: 25. Tithonia diversifolia. BALSAMINACEAE: 26. Impatiens walleriana. BIGNONIACEAE: 27. Tabebuia rosea.

Figura 6S. BORAGINACEAE: 28. Cordia alba. 29. Cordia alliodora. 30. Cordia spinescens.

Figura 7S. CANNABACEAE: 31. Celtis iguanaea. CHRYSOBALANACEAE: 32. Chrysobalanus icaco. CLUSIACEAE: 33. Clusia multiflora. CONVOLVULACEAE: 34. Ipomoea batatas.

Figura 8S. CONVOLVULACEAE: 35. Merremia umbellata. ELAEOCARPACEAE: 36. Sloanea multiflora.

ERYTHROXYLACEAE: 37. Erythroxylum novogranatense. ESCALLONIACEAE: 38. Escallonia pendula.

Figura 9S. EUPHORBIACEAE: 39. Acalypha macrostachya. 40. Alchornea latifolia. 41. Euphorbia hirta. 42. Ricinus communis. 43. Sapium glandulosum.

FABACEAE (FABOIDEAE): 44. Aeschynomene americana. 45. Erythrina rubrinervia.

Figura 10S. FABACEAE (FABOIDEAE): 46. Trifolium repens. FABACEAE (MIMOSOIDEAE): 47. Mimosa pigra. HYPERICACEAE: 48. Vismia baccifera. ICACINACEAE:
49. Calatola costaricensis. LAMIACEAE: 50. Hyptis mutabilis. 51. Salvia occidentalis. LAURACEAE: 52. Persea americana. LYTHRACEAE: 53. Adenaria floribunda.

Figura 11S. MALPIGHIACEAE: 54. Stigmaphyllon columbicum. MALVACEAE (BOMBACOIDEAE): 55. Ceiba pentandra. 56. Ochroma pyramidale. 57. Pseudobombax septenatum.

Figura 12S. MALVACEAE (BYTTNERIOIDEAE): 58. Melochia parvifolia (a-b: morfotipo 1, c-d: morfotipo 2). MALVACEAE(GREWIOIDEAE): 59. Corchorus orinocensis. MALVACEAE (MALVOIDEAE): 60. Abutilon $x$ hybridum. MELASTOMATACEAE: 62. Conostegia icosandra.

Figura 13S. MALVACEAE (MALVOIDEAE): 61. Sida acuta. MELASTOMATACEAE: 63. Miconia dodecandra. 64. Miconia minutiflora. 65. Miconia serrulata. 66. Tibouchina longifólia. MORACEAE: 67. Pseudolmedia laevigata. 68. Trophis racemosa. MYRTACEAE: 69. Calycolpus moritzianus.

Figura 14S. MYRTACEAE: 70. Eucalyptus globulus. 71. Myrcia splendens. 72. Psidium guajava. 73. Syzygium jambos. PHYTOLACCACEAE: 74. Phytolacca rivinoides. POLYGONACEAE: 75. Triplaris americana.

PROTEACEAE: 76. Roupala montana. RUBIACEAE: 77. Spermacoce verticillata.

Figura 15S. RUBIACEAE: 78. Warszewiczia coccínea. RUTACEAE: 79. Citrus aurantium. SALICACEAE: 80. Casearia corymbosa.

SAPINDACEAE: 81. Cupania americana. 82. Paullinia macrophylla. 83. Serjania paniculata.

Figura 16S. SOLANACEAE: 84. Brugmansia pittieri. 85. Solanum aturense.

VITACEAE: 86. Cissus verticillata.
Colombiano y a la colección palinológica del ICN, a Marta Quicazán y Consuelo Díaz, por su apoyo, y al equipo del Laboratorio de Investigaciones en Abejas, LABUN, por su colaboración en los procedimientos palinológicos.

\section{Bibliografía}

Anónimo (2013). Biodiversidad: Comunidades vegetales. Fundación Pro Sierra Nevada de Santa Marta. Fecha de consulta: 7 de octubre de 2013. Disponible en: http://www.prosierra.org/ index.php?option=com_wrapper\&view=wrapper\&Itemid $=94$.

Anónimo (2003). Consolidación de la gestión y el ordenamiento territorial en la ecorregión de la Sierra Nevada de Santa Marta, Barranquilla: Ministerio del Medio Ambiente, Consejo Ambiental Regional de la Sierra Nevada de Santa
Marta. Corporación Melquíades. p.76.

Bernal, R., Galeano, G., Rodríguez, A., Sarmiento, H., Gutiérrez, M. (2013). Nombres Comunes de las Plantas de Colombia. Fecha de consulta: 3 de octubre de 2013. Disponible en: http:/www.biovirtual.unal.edu.co/nombrescomunes/.

Castaño, S. I. \& Fonnegra R. (1981). Análisis polínico en miel de abejas de algunas regiones de Antioquia. Revista de la Asociación Colombiana de Ciencias Biológicas. 3 (3): $100-110$

Crane, E. (1985). El libro de la miel. Breviarios, 349. México: Fondo de Cultura Económica. p. 289.

Echeverry, E. R. (1984). Flora apícola colombiana. Bogotá: Presidencia de la República de Colombia. p. 283.

Erdtman, G. (1943). An introduction to pollen analysis. Waltham 
Mass.: Chronica Botanica Co. p. 239.

Espinal, S. \& Montenegro, G. (1963). Formaciones vegetales de Colombia: memoria explicativa sobre el mapa ecologíco. Bogotá D.E.: Instituto Geografico Agustin Codazzi. p. 238.

Giraldo, C., Rodríguez, A., Chamorro, F., Obregón, D., Montoya, P., Ramírez, N., Solarte, V., Nates-Parra, G. (2011). Guía Ilustrada de polen y plantas nativas visitadas por abejas. Bogotá D.C.: Universidad Nacional de Colombia. p. 230.

Girón Vanderhuck, M. (1995). Análisis palinólógico de la miel y la carga de polen colectada por Apis mellifera en el suroeste de Antioquia, Colombia. Bol. Mus. Ent. Univ. Valle. 3 (2): $35-54$.

Hooghiemstra, H. (1984). Vegetational and climatic history of the high plain of Bogotá, Colombia. Dissertaciones Botanicae, 79: p. 368

Jiménez, L.C. \& Rangel, J.O. (1997). Atlas Palinológico de la Amazonia Colombia II. Familia Asteraceae. Caldasia. 19 (1-2): 29-39.

León-Bonilla, D. (2014) Análisis polínico de mieles de cultivos orgánicos y convencionales de la Sierra Nevada de Santa Marta. Tesis de Maestría. Universidad Nacional de Colombia. Bogotá. Manuscrito en preparación.

Louveaux, J., Maurizio, A. \& Vorwohl, G. (1970). Methods of melissopalynology. Bee World. 51 (3): 125-138.

Nates-Parra, G., Montoya, P.M., Chamorro, F., Ramírez, N., Giraldo, C., Obregón, D. (2013). Origen geográfico y botánico de mieles de Apis mellifera (Apidae) en cuatro departamentos de Colombia. Acta Biológica Colombiana. 18 (3): 427-238.

Nicolson, S. W., Nepi, M. \& Pacini, E. (2007). Nectaries and nectar. Dordrecht: Springer. p. 395.

Palacios-Chávez, R., B. Ludlow-Wiechers, R., \& Villanueva G. (1991). Flora palinológica de la reserva de la biosfera de Sian Kaán, Quintana Roo, México. Chetumal, Quintana Roo: Centro de Investigaciones de Quintana Roo. p. 321.

Punt, W., Hoen, P.P., Blackmore, S., Nilsson, S., Le Thomas, A. (2007). Glossary of pollen and spore terminology. Review of Palaeobotany and Palynology. 143: 1-81.

Rangel, J.O. \& Bogotá, R.G. (2001). Atlas Palinológico de la Amazonia Colombiana IV. Familia Arecaceae. Caldasia. 23 (1): $281-300$.

Roubik, D. W. \& Moreno J. E. (1991). Pollen and spores of Barro Colorado Island. Monographs in Systematic Botany. St. Louis, Montana, United States: Missouri Botanical Garden. p. 270.

Sánchez, D. (1995). Calendarios apícolas para el suroeste antioqueño. Miscelanea Sociedad Colombiana de Entomología. 32: $1-40$.

Velandia, M., Restrepo, S. Cubillos, P., Aponte, A., Silva, L.M. (2012). Catálogo fotográfico de especies de flora apícola en los departamentos de Cauca, Huila y Bolívar. Bogotá: Instituto Humboldt. p. 84.

Velásquez, C. (1999). Atlas palinológico de la flora vascular paramuna de Colombia: Angiospermae. Medellín: Universidad Nacional de Colombia. p. 173.

Von der Ohe, W., Persano-Oddo, L., Piana, M.L., Morlot, M., Martin, P. (2004). Harmonized methods of melissopalinology. Apidologie. 35: S18-S25. 